Document downloaded from:

http://hdl.handle.net/10251/104010

This paper must be cited as:

García Valladolid, P.; Tunestål, P.; Monsalve-Serrano, J.; García Martínez, A.; Hyvönen, J. (2017). Impact of diesel pilot distribution on the ignition process of a dual fuel medium speed marine engine. Energy Conversion and Management. 149:192-205.

doi:10.1016/j.enconman.2017.07.023

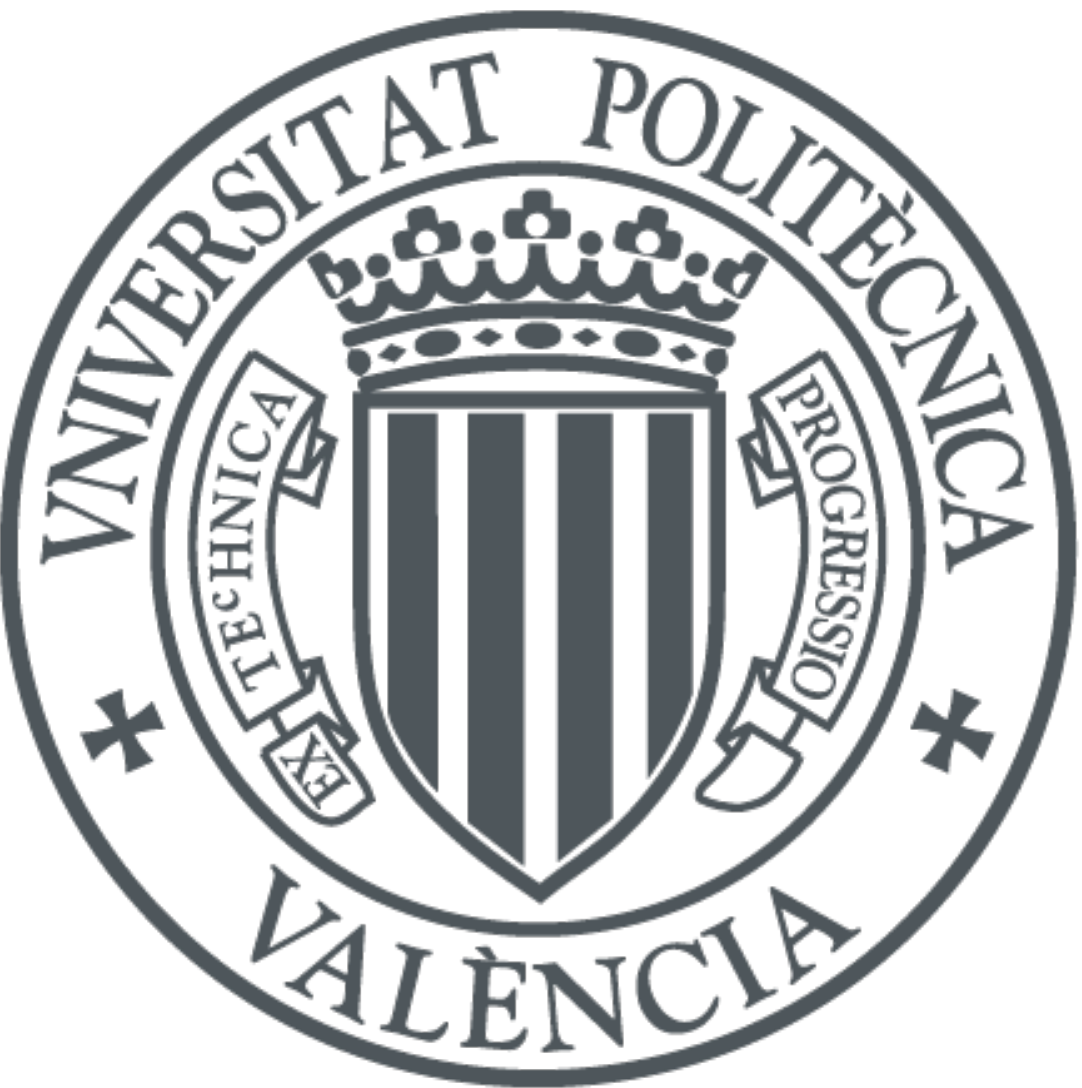

The final publication is available at

http://doi.org/10.1016/j.enconman.2017.07.023

Copyright Elsevier

Additional Information 


\title{
Impact of Diesel Pilot Distribution on the Ignition Process of a Dual Fuel Medium Speed Marine Engine
}

\author{
Pablo García Valladolid ${ }^{\mathrm{a}, *}$, Per Tunestål ${ }^{\mathrm{a}}$, Javier Monsalve-Serrano ${ }^{\mathrm{b}}$, Antonio \\ García $^{\mathrm{b}}$ \\ ${ }^{a}$ Department of Energy Sciences, Lund University, Ole Römers Väg 1, 22363 Lund, Sweden \\ ${ }^{b}$ CMT-Motores Térmicos, Universitat Politècnica de València, Camino de Vera s/n, 46022 \\ Valencia, Spain
}

\begin{abstract}
Recent emission legislation in the marine sector has emphasized the need to reduce nitrogen oxides $\left(\mathrm{NO}_{x}\right)$ emissions as well as sulphur emissions. Certain special sea areas, regulated by the MARPOL Convention, are provided with a higher level of protection due to their oceanographical and ecological conditions. The fulfilment of these limits with conventional marine diesel oil (MDO) requires complex and expensive aftertreatment systems and in this framework lean burn dual fuel (diesel and natural gas) is revealed as one of the most suitable engine platforms to decrease pollutant formations at its source and therefore to mitigate aftertreatment system requirements. For these reasons, the share of dual fuel natural gas engines in the marine market is growing, apart from well-known fuel flexibility and other benefits that the concept can provide to customers. During dual fuel operation diesel fuel is used as the source of ignition of natural gas. Traditionally, diesel fuel is injected close to top dead center, when thermodynamic conditions in the combustion chamber lead to a short ignition delay. However, high cylinder local temperatures due to fuel stratification and diffusion combustion enhance $\mathrm{NO}_{x}$ formation and the risk of knocking cycles. For this reason, an experimental study has been carried out in an 8.8 liter dual fuel single cylinder Wärtsilä 20DF engine in order to evaluate different diesel
\end{abstract}

\footnotetext{
*Corresponding author

Email address: pablo.garcia@energy.1th.se (Pablo García Valladolid)
} 
equivalence ratio distributions in the combustion chamber and to get a deeper insight into the interaction between the high reactivity (diesel) and the low reactivity (natural gas) fuels during the ignition process. Engine testing has been complemented with diesel spray pattern simulations for a better understanding of local combustion conditions. Results show the importance of local pilot fuel distribution as a way to control combustion phasing and consequently its impact on combustion stability, emissions and knock conditions. Stable combustion with engine-out $\mathrm{NO}_{x}$ levels below legislation have been achieved without the need of after-treatment system using appropriate high reactivity fuel (HRF) distribution control. The results include analysis of pilot injection timings, pilot injection pressure and thermodynamic conditions.

Keywords: Natural Gas, Ignition, Pilot Injection, Dual Fuel 2010 MSC: 00-01, 99-00

\section{Introduction}

\subsection{Emission Legislation for Marine and Stationary Engines}

The International Maritime Organization (IMO) is the main agency responsible of the prevention of marine pollution by ships. IMO created the first key 5 anti-pollution protocol in 1978, which was addressed during the International Convention for the Prevention of Pollution from Ships (MARPOL) held in 1973 and which entered into force in 1983. MARPOL has been updated via different amendments throughout the years. The convention includes not only limits on pollutant emissions but also strategies and regulations to prevent and minimize pollution from ships [1].

Regarding air pollution, the 1997 Annex VI to MARPOL (TIER I) introduced a new set of regulations in order to minimize emissions from ships and entered into force in 2005. Special focus was put on sulphur oxides $\left(\mathrm{SO}_{x}\right)$ and nitric oxides $\left(\mathrm{NO}_{x}\right)$. After that, other revisions have been applied to MARPOL annex VI which have strengthened the emission limits in special emission control areas (ECA). In these areas, more stringent requirements are applicable 
Table 1: TIER $\mathrm{NO}_{x}$ Emission Limits for 1000 rpm engines [2]

\begin{tabular}{lll} 
Tier & Ship Construction from: & Limit $[\mathrm{g} / \mathrm{kWh}]$ \\
\hline I & 1 January 2000 & 11.3 \\
II & 1 January 2011 & 8.98 \\
III & 1 January 2016 & 2.26 \\
\hline
\end{tabular}

to ships, usually related to $\mathrm{SO}_{x}$, particulate matter $(\mathrm{PM})$ and $\mathrm{NO}_{x}$. Recently, TIER II (for ships constructed after 1st January 2011) and TIER III (for ships constructed after 1st January 2016) emission limits have introduced more severe limits. The different TIER $\mathrm{NO}_{x}$ emission limits are depicted in Table 1. Regarding $\mathrm{SO}_{x}$ emissions, MARPOL currently establishes a global limit of $3.5 \%$ ( $0.1 \%$ in ECAs) in fuel and it includes reduction to $0.5 \%$ by 2020 [2]

Medium speed marine engines are also utilized for other purposes besides mechanical-drive prime mover in small applications (small cargo vessels, ferries, etc.). It is common to see medium speed marine engines as stationary engines for power production, so called generating sets. In these cases, other emission legislation may apply. One of the most stringent emission legislations for stationary sources is the Technische Anleitung zur Reinhaltung der Luft, usually referred to as TA Luft. The TA Luft limits are considered strict. In this case, a 30 $\mathrm{NO}_{x}$ limit of $0.5 \mathrm{~g} / \mathrm{Nm}^{3} @ 5 \% \mathrm{O}_{2}$ (vol.) applies for dual fuel applications, which usually translates into limits below $1 \mathrm{~g} / \mathrm{kWh}$, depending on engine operation.

$\mathrm{SO}_{x}$ and $\mathrm{NO}_{x}$ limits on emissions have caused the industry to find alternatives to traditional diesel combustion. New diesel marine engines usually require the use of $\mathrm{SCR}$ catalyst and $\mathrm{SO}_{x}$ scrubbers in order to meet legislation, due to 35 the limited availability and high cost of low sulphur marine fuel. These factors are driving the use of natural gas as marine fuel, since it meets the requirements of MARPOL Annex VI in both $\mathrm{SO}_{x}$ (practically sulphur free fuel) and $\mathrm{NO}_{x}$ (depending on engine operating mode). Moreover, natural gas is lower priced than MDO or heavy fuel oil (HFO) in certain markets. Uncertainty about when the 40 $\quad 0.5 \%$ Annex VI SO $\mathrm{S}_{x}$ limit will enter into force and the possible future expansion 
of the number of ECAs have also boosted research on natural gas as marine fuel [3].

\subsection{Pilot Ignited Dual Fuel Engines}

Traditionally, natural gas has been used in spark ignition (SI) engines due to its similar combustion characteristics to gasoline-like fuels, where a simple gas injection system can be added and the engine is operated in bi-fuel mode. However, the reduced compression ratio of SI engines limits theoretical maximum thermal efficiency. For this reason, among others, the interest of natural gas combustion in compression ignition (CI) engines has increased in the latest years. The most common use of natural gas in CI engines is via pilot ignited dual fuel combustion, where a small amount of HRF is used to ignite a quasihomogeneous natural gas and air mixture. In most cases, natural gas is injected in the intake port during the intake stroke, although some direct injection applications exist [4, 5].

In terms of pollutant emissions, natural gas intrinsically offers benefits in terms of carbon dioxide emissions $\left(\mathrm{CO}_{2}\right)$ due to its low carbon-to-hydrogen ratio, although unburned methane can significantly decrease its greenhouse benefits if combustion efficiency is not maximized. Mixture trapped in piston top land crevices and flame quenching in the bulk charge are the most important sources of unburned hydrocarbons (UHC) [6. Both direct injection [7] and optimization of combustion chamber geometry [8] have potential for reducing UHC emissions from natural gas engines. While light duty and heavy duty engine emission standards have introduced limits on UHC emissions, few emission legislations for marine and stationary engines have addressed this problem and consequently this topic has not severely limited the implementation of natural gas engines in these sectors. However, these emissions are expected to be regulated in the future for stationary and marine applications [9. Pilot ignited natural gas combustion offers great advantages in terms of particulate matter (PM), especially for cases where pilot fuel mass represents less than $10 \%$ of the 70 total energy content [10, 11, 12]. Regarding $\mathrm{NO}_{x}$ emissions, the performance of 
dual fuel combustion engines strongly depends on the HRF combustion characteristics, which are mainly determined by the HRF injection settings selected (HRF injection timing, injection pressure and fuel mass). Under lean gas-air mixture conditions, the $\mathrm{NO}_{x}$ production is mainly confined to the HRF fuel cloud, where high combustion temperature is reached. Some further $\mathrm{NO}_{x}$ production is produced in the vicinity of the pilot combustion zone due to the interaction between the low reactivity fuel (LRF) and HRF [13. Minimization of the relative $\mathrm{HRF}$ pilot mass is traditionally used for reducing $\mathrm{NO}_{x}$ production. However, excessively small pilot size can turn out in insufficient ignition energy for the given gas-mixture characteristics, which as consequence results in poor combustion efficiency, increased UHC and reduced combustion stability. On the other hand, high amounts of HRF can produce even more $\mathrm{NO}_{x}$ than conventional diesel combustion and the increased combustion temperatures can cause knock.

The dual fuel combustion process is usually divided into 3 different stages. The first one consists of the HRF injection time. Pilot Injection timing, pressure and fuel mass are crucial parameters in dual fuel combustion, since ignition delay is heavily affected by these parameters [14]. The HRF is mixed with the gas-air mixture until ignition takes place. This second stage, defined by HRF 90 Ignition, depends on HRF fuel distribution and thermodynamic conditions (temperature, pressure and oxygen concentration) in the combustion chamber and this is where the ignition delay is determined [15]. This is usually characterized by ignition of the gas-mixture in the vicinity of the pilot spray [16. Finally, LRF ignition and flame propagation take place in the remainder gas-air mixture and it highly depends on the reactivity of gas-mixture and the charge thermodynamic conditions, since the flammability of a natural gas mixture is highly affected by these parameters [17].

In recent years, alternative combustion modes for dual fuel engines have been investigated in an attempt to overcome the limitations of traditional combustion 100 modes. One of the most relevant alternative combustion modes for dual-fuel applications is Reactivity Controlled Compression Ignition (RCCI) [18, 19, 20]. In 


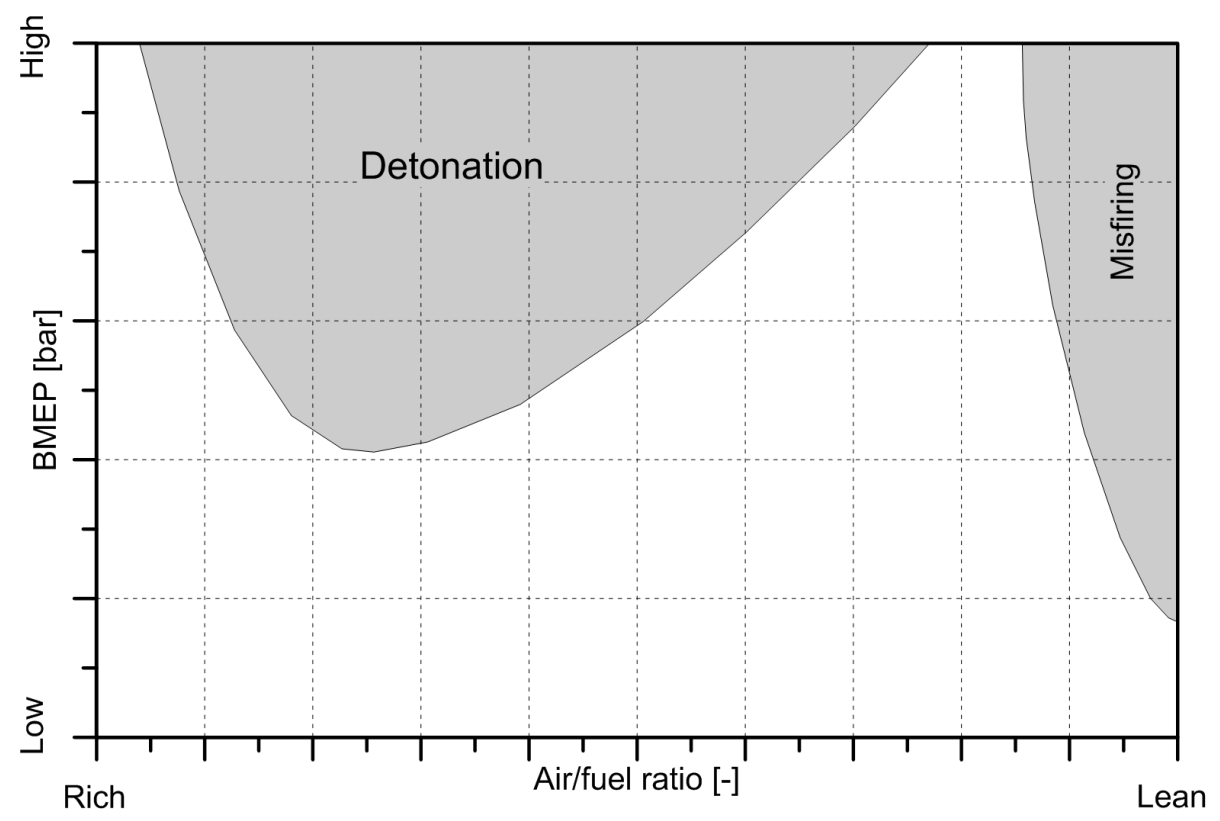

Figure 1: Example of dual fuel engine operating conditions and detonation/misfiring regions

this concept, the HRF fuel in the combustion chamber is controlled in order to promote mixing within the LRF and control the combustion characteristics via the reactivity of the mixture. In the context of diesel pilot ignited natural gas combustion, early HRF fuel injection timings allow a longer mixing time of HRF fuel with the main charge. Consequently, it is expected that the HRF fuel interacts and affects the LRF fuel in a different manner compared to traditional late pilot injection timings, especially for applications where HRF mass is minimized. This hypothesis suggests the need for detailed knowledge about HRF stratification and ignition characteristics in order to explain the emissions and performance levels of dual fuel applications. In this context, this paper is designed to provide a deeper insight into the ignition characteristics of pump diesel fuel in natural gas-air mixtures, with focus on the ignition characteristics and its effects on the main charge combustion. 


\subsection{Boundaries}

Pilot ignited dual fuel combustion is highly sensitive to mixture global equivalence ratio [16, 21]. Instabilities could appear under excessively lean conditions, while engine operation could be limited by abnormal combustion (knocking) under richer conditions. High ignition energy, and consequently high pilot fuel mass, could result in excessively high local temperatures in the combustion chamber, which enhances knocking probability, even from medium load operation. On the other hand, low pilot fuel ignitability or excessively lean gas mixture can cause poor combustion stability through the mixture and consequently misfiring behaviour. This trade-off is presented in Figure 1.

\subsection{Objective}

The main objective of this paper is to identify the links between HRF combustion characteristics and the ignition process of the LRF mixture and to understand how HRF autoignition affects LRF combustion characteristics. The different operating conditions evaluated in this paper are not specifically selected for the fulfilment of operating boundaries and emission legislation. The main goal is to provide a deeper insight about how HRF distribution in the combustion chamber should be controlled and to explain why its appropriate control can lead to excellent benefits in terms of performance and emissions. Simulations of HRF equivalence ratio distribution in the combustion chamber at start of combustion $(\mathrm{SoC})$ have been performed. The main hypothesis is based on the fact that traditional pilot ignited dual fuel combustion relies on HRF stratification for sustained combustion stability, despite higher local combustion temperatures and risk of knocking. Controlling HRF autoignition by reducing stratification in the combustion chamber may reduce combustion temperatures and consequently lower $\mathrm{NO}_{x}$ emissions as well as reduce risk of abnormal combustion events. 
Table 2: Single Cylinder Engine Specifications

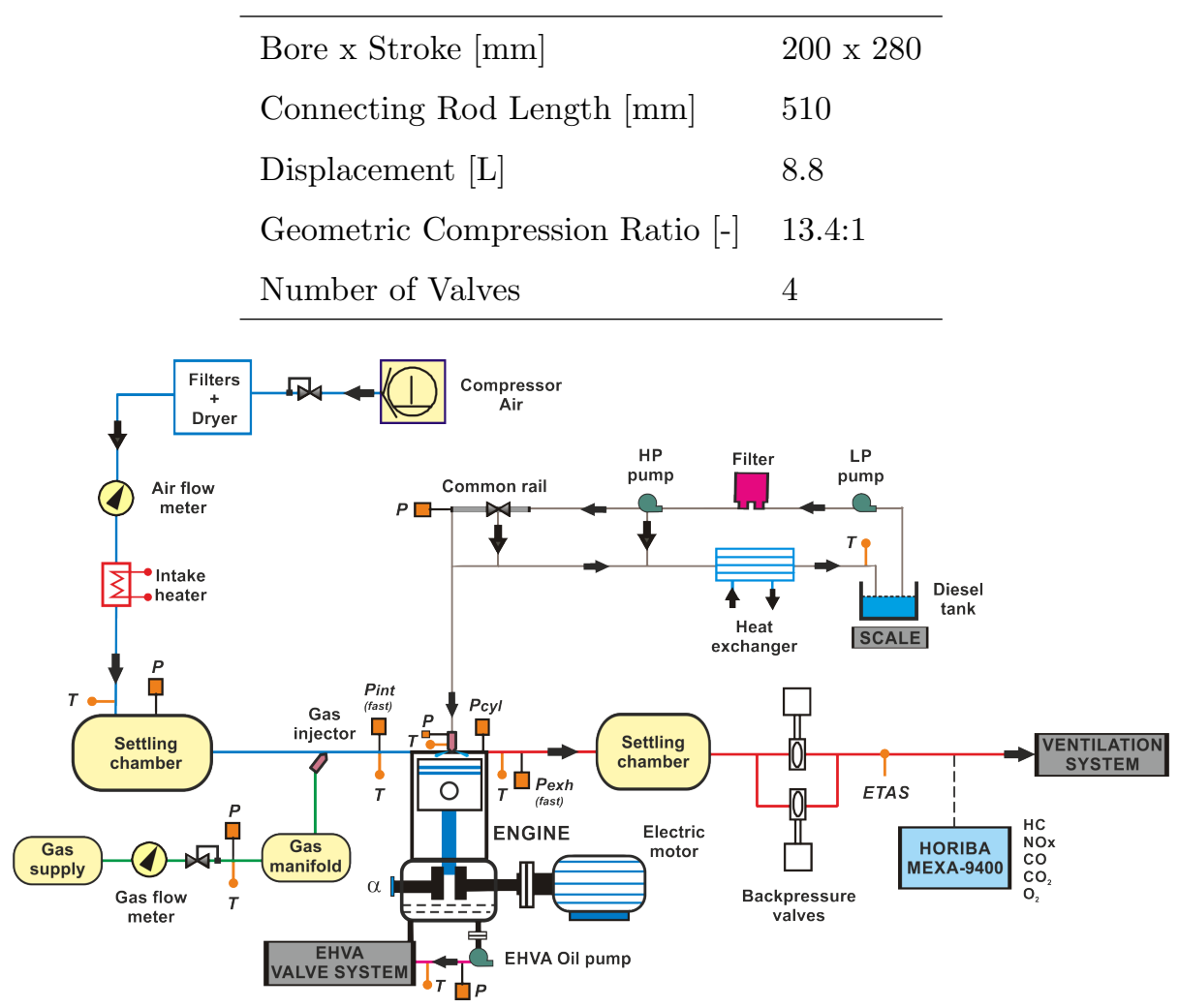

Figure 2: Engine test cell layout

\section{Experimental Facilities and Processing Tools}

\subsection{Experimental Setup}

\subsubsection{Test Cell Description and Instrumentation}

In this section, a description of the engine test cell facility where investigations were carried out is presented. Experiments have been performed using a Wärtsilä 20 DF engine, modified for single-cylinder operation and equipped with electro-hydraulic valve actuation (EHVA) and diesel common rail injection system. The EHVA system is based on two independent Parker D3FP directoperated proportional DC valves [22. Main engine specifications are presented in Table 2, 
Table 3: Properties of the fuels used along the study

\begin{tabular}{lll}
\hline & Diesel MK1 & Natural Gas \\
\hline Density $\left[\mathrm{kg} / \mathrm{m}^{3}\right]\left(\mathrm{T}=15^{\circ} \mathrm{C}\right)$ & 812.4 & 0.824 \\
Viscosity $\left[\mathrm{mm}^{2} / \mathrm{s}\right]\left(\mathrm{T}=40^{\circ} \mathrm{C}\right)$ & 2.017 & - \\
Methane Number $[-]$ & - & 71.7 \\
Methane Content [\% Vol] & - & 88.9 \\
Cetane Number [-] & 51 & - \\
Lower Heating Value $[\mathrm{MJ} / \mathrm{kg}]$ & 43.1 & 48.1 \\
\hline
\end{tabular}

The engine is instrumented with the necessary equipment required for its operation and control, as illustrated in Figure 2. Due to the large displacement of the engine, receiver tanks are installed before and after the engine, as shown air was supplied to the setup. Both intake pressure and temperature were controlled at the intake manifold independently. The engine was not equipped with exhaust gas recirculation system (EGR). Exhaust backpressure was regulated by the use of two backpressure valves located in the exhaust path (coarse-tofine method). The engine is equipped with intake and exhaust piezorresistive pressure transducers Kistler 4075A10. The concentrations of $\mathrm{NO}_{x}, \mathrm{CO}, \mathrm{CO}_{2}$, unburned $\mathrm{HC}$ and $\mathrm{O}_{2}$ were obtained using a Horiba MEXA-9400 motor exhaust gas analyser Finally, in-cylinder pressure was measured using a water-cooled Kistler 7061B piezoelectric pressure transducer connected to a Kistler 5011B10 charge amplifier. High temporal resolution was obtained by sampling signals every 0.2 CAD via a Kistler 2614CK crank angle encoder.

\subsubsection{Fuels}

In this investigation, two different fuels have been used. Swedish MK1 diesel was used as HRF, which follows SS-15 5435 and EN590 diesel standards. On 170 the other side, natural gas was obtained from south-west Sweden's national grid and was used as LRF. Their main properties are listed in Table 3. 
Table 4: Main characteristics of the diesel injector

\begin{tabular}{ll}
\hline Type & Solenoid \\
Steady Flow Rate @ 100 bar [ml/min] & 4940 \\
Number of Holes [-] & 9 \\
Hole Diameter $[\mu \mathrm{m}]$ & 295 \\
Spray Angle $\left[{ }^{\circ}\right]$ & 156 \\
\hline
\end{tabular}

Diesel fuel was injected into the combustion chamber using a common rail diesel injection system. Since the test engine used is originally equipped with jerk fuel pumps, modifications to the fuel system were necessary to adapt it to common rail technology. A Scania XPI fuel pump was installed, driven by an electrical motor run at a constant speed of 500rpm. Since the fuel pump is not designed for pilot ignition engine operation, a high pressure valve was installed in the common rail in order to increase the fuel flow through the fuel pump and avoid overheating. A weighting scale was used for measuring diesel fuel flow. The L'orange VTO-G255 diesel injector was used and the main characteristics are depicted in Table 4

Regarding natural gas injection, the original port injection fuel system remained unaltered. It consisted of a SOGAV 43 solenoid operated gas admission valve which injected the fuel directly into the intake port. Natural gas supplied pressure was adjusted via a remotely controlled valve which guaranteed 1 bar of pressure drop over the gas valve. Natural gas flow was measured using a Bronkhorst F-106AI thermal mass flow meter.

\subsection{Theoretical Tools}

\subsubsection{Analysis of in-cylinder pressure signal}

The combustion analysis was performed based on the apparent heat release model (heat losses were not included) with variable heat capacity ratio during compression and expansion strokes, which is introduced in Equation 1. The heat release analysis presented here is a 0-D model calculated in an interval of 
120 crank angles around TDC where multiple assumptions and simplifications are made to simulate a complex system with significant spatial variations in pressure, temperature and composition. The pressure traces from 300 consecutive engine cycles were recorded in order to evaluate cycle-to-cycle variations during engine operation. No filtering was applied to cylinder pressure data, but the calculated apparent heat release traces were filtered using a low-pass digital Butterworth filter. This was performed due to the presence of in-cylinder pressure oscillations in the combustion chamber due to premixed diesel combustion. Combustion analysis was performed based on the resulting cylinder pressure and heat release traces.

$$
\frac{d Q}{d t}=\frac{\gamma}{\gamma-1} p \frac{d V}{d \theta}+\frac{1}{\gamma-1} V \frac{d p}{d \theta}
$$

Start of combustion (SoC) was defined as the crank angle at which the accumulated heat release reached $5 \%$ and combustion phasing was determined using CA50 definition (crank angle position of $50 \%$ fuel mass fraction burned). As a measure of combustion variability, the coefficient of variation of $I M E P_{G}(\mathrm{COV})$ was used and it was defined as:

$$
C O V=\frac{\sigma_{I M E P_{G}}}{\mu_{I M E P_{G}}}
$$

where $\sigma$ and $\mu$ are the standard deviation and the mean value respectively over 300 consecutive cycles. Finally, in-cylinder pressure oscillations were evaluated using the integral of modulus of pressure gradient (IMPG), which is defined by:

$$
I M P G=\frac{1}{N} \sum_{n=1}^{N} \int_{\theta_{0}}^{\theta_{0}+\xi}\left|\frac{d \hat{p}}{d \theta}\right| d \theta
$$

where $\hat{\mathrm{p}}$ is the filtered pressure trace (bandpass filter) and $\theta_{0}$ and $\theta_{0}+\xi$ define the beginning and the end of the crank angle window. The proper filtering frequencies were estimated using C.S Draper's acoustic pressure wave theory [23, where speed of sound was calculated under the assumption that the premixed charge behaved as an ideal gas. This resulted in cut-off frequencies at 2 and $8 \mathrm{kHz}$ repectively. The IMPG knocking level is proportional to the ringing intensity estimator which is commonly used in CI combustion [24, 25, 26]. 


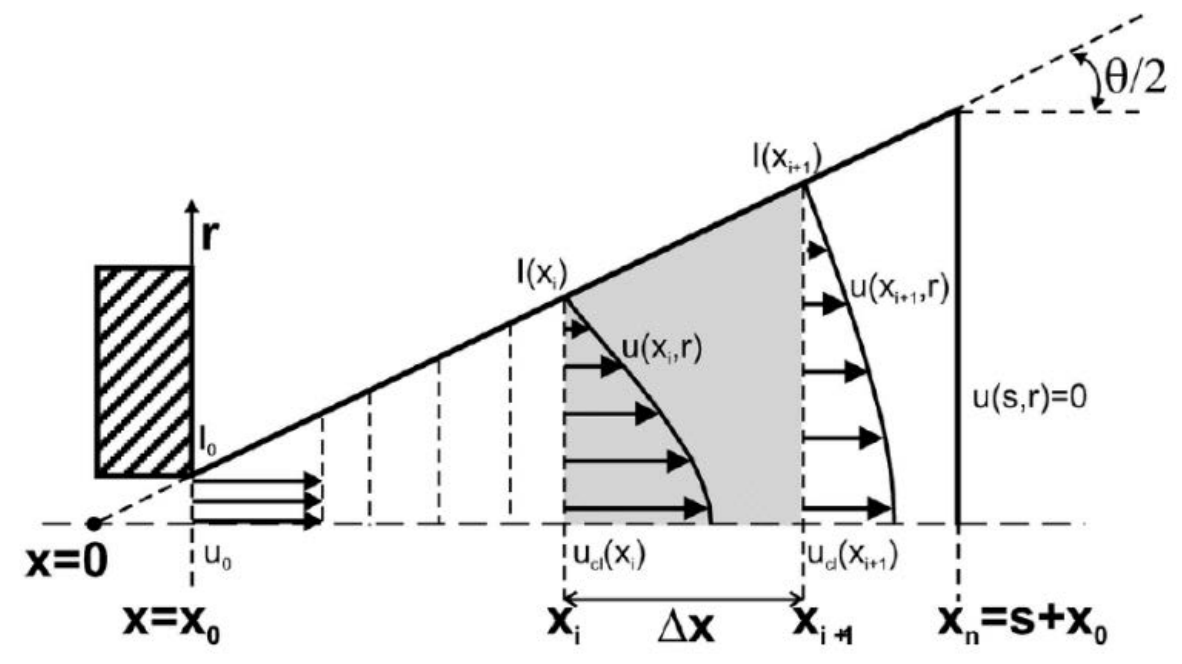

Figure 3: DICOM model description

Finally, in-cylinder temperature has been estimated using a single zone model based on the ideal gas law, where the constant term is evaluated at IVC and assumed constant during the heat release calculation interval.

\subsubsection{Fuel distribution definitions}

The analysis of fuel distribution in terms of global and single fuel equivalence ratios is explained in this section. Two fuels with different lower heating values (LHV) were present in the combustion chamber during the combustion process. Gas fraction based on energy content is defined in Equation 4 In this study, diesel energy was slightly changed between different engine loads. Consequently, the gas fraction increased with engine load. Global effective equivalence ratio was calculated via analysis of exhaust components ( 5 component analysis, water content estimated) 27. while single fuel equivalence ratio was defined using the traditional equivalence ratio definition.

$$
G F=\frac{\dot{m}_{C N G} \cdot L H V_{C N G}}{\dot{m}_{C N G} \cdot L H V_{C N G}+\dot{m}_{\text {Diesel }} \cdot L H V_{\text {Diesel }}} \cdot 100
$$




\subsubsection{Analysis of mixing process}

An in-house developed 1D spray model called DICOM [28, 29] has been used to perform the mixing process analysis. The main assumption of the model is that the fuel spray is injected into a quiescent air volume large enough to avoid modifications of the air conditions far away from the injector nozzle. This assumption is reasonable considering the dimensions of the engine used in this research (8.8 L, single cylinder engine). With this hypothesis, the 1D model solves the air-fuel mixing process considering a problem domain as that shown in Figure 3 . In the vicinities of the nozzle, a uniform fuel flow velocity profile is assumed. The velocity profile is modified as the fuel flow exchanges momentum with the in-cylinder charge, leading to a cone angle that increases in width with the axial distance. The origin of the spray is defined as $X_{0}=d_{0} / 2 / \tan (\theta / 2)$, for which the spreading angle $(\theta / 2)$ and nozzle diameter $\left(d_{0}\right)$ are given as inputs to the model. To solve the mathematical problem that represents the mixing process, the axial spray domain is divided into cells of thickness $\mathrm{x}$. Each cell is delimited by the inlet and the outlet sections ( $i$ and $i+1$, respectively), satisfying $x_{i+1}=x_{i}+\Delta x$.

Required inputs for the model are the spray cone angle $(\theta)$, spray momentum $\left(I_{0}\right)$ and mass flux $\left(M_{0}\right)$ at the nozzle exit. In addition, the thermodynamic conditions from the engine experiments are also necessary. Thus, the 1D model solves the general conservation equations for axial momentum and fuel mass in terms of the on-axis (i.e., center line) referred to instantaneous values of velocity and species mass fractions. Then, assuming self-similar conditions, the conservative properties are extrapolated radially through a radial Gaussian profile [30. Local temperature, density and composition can also be calculated through state relationships. The instantaneous spray penetration (S) is defined as the axial position of the cell which satisfies that inlet and outlet velocities are non-zero and zero, respectively. An extensive explanation of the calculation process and the hypotheses assumed by the model can be found in [31.

230 To consider the dual-fuel operation [32, two additional inputs are required 


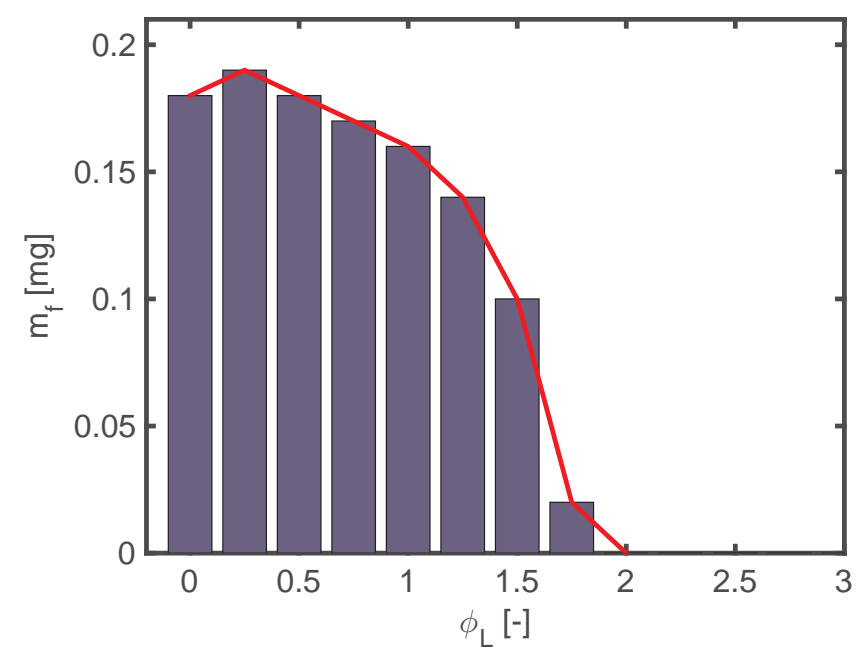

Figure 4: Example of histogram and envelope curve of fuel mass distribution mixed to different equivalence ratios at the experimental SoC

to define the in-cylinder charge conditions before the diesel fuel injection occurs, i.e. when only fresh air and natural gas coexist. The two inputs are the oxygen mass fraction at intake valve closing (IVC) and the stoichiometric equivalence ratio of the in-cylinder fuel blend, which is calculated as shown in Equation 5 .

$$
\begin{array}{r}
\phi_{e s t}=\frac{1-\phi_{L R F}}{C_{H R F}+\frac{H_{H R F}}{4}} \times \frac{12 C_{H R F}+H_{H R F}}{32} \times \\
1+\frac{1}{Y_{N_{2}, I V C}, I V C}+\phi_{L R F} \times \frac{1}{C_{L R F}+\frac{H_{H R F}}{4}} \times \frac{12 C_{L R F}+H_{L R F}}{32}
\end{array}
$$

where $\phi_{L R F}$ and $\phi_{H R F}$ are respectively the absolute equivalence ratios of the LRF (natural gas) and HRF (diesel), $C_{H R F}, C_{L R F}, H_{H R F}, H_{L R F}$ denote the number of carbon and hydrogen atoms, while $Y_{N_{2}, I V C}$ and $Y_{O_{2}, I V C}$ stand for the nitrogen and oxygen mass fraction at IVC, respectively.

For each test analysed, the mixing process calculations begin at the start of injection timing of diesel fuel $\left(S O I_{H R F}\right)$ and the data analysis is performed at the start of combustion ( $\mathrm{SoC}$ ) timing, which is obtained from the experimental data. The results presented in the manuscript have been post-processed to show the diesel fuel mass distribution mixed to different equivalence ratios at $\mathrm{SoC}$ in 
the form of histograms, as shown in Figure 4. For the sake of clarity, only the ensettings on performance and emissions.

\section{Methodology}

A series of parametric studies was performed in single-cylinder engine configuration and complemented with simulations. Global equivalence ratio was in order to reduce the risk of knocking cycles and represents realistic operating conditions of the production engine. The engine was operated without EGR and with constant valve timings, except for IVC, which was varied in order to test different thermodynamic conditions in the combustion chamber and to reduce bustion stability. At medium load conditions, diesel injection timing was varied between stability limits at three different pilot injection pressures. At these conditions, peak in-cylinder pressure was not a limiting factor due to reduced engine load and lean conditions. However, limitations in terms of combustion stability other hand, high load operation was limited by maximum peak in-cylinder pressure with retarded injection timing, while stability became a limiting factor for 
Table 5: Common settings for all points

\begin{tabular}{ll}
\hline Speed $[\mathrm{rpm}]$ & 1000 \\
EGR $[\%]$ & 0 \\
Coolant Temperature $\left[{ }^{\circ} \mathrm{C}\right]$ & 80 \\
IVO [CAD bTDC] & 5 \\
EVO [CAD bBDC] & 35 \\
EVC [CAD aTDC] & -10 \\
CNG Injection Timing [CAD bTDC] & 330 \\
Global Equivalence Ratio [-] & 0.5 \\
\hline
\end{tabular}

Table 6: Settings for medium and high load operating conditions

\begin{tabular}{lll}
\hline & $\begin{array}{l}\text { Medium Load } \\
\text { 10bar IMEPg }\end{array}$ & $\begin{array}{l}\text { High Load } \\
19 \text { bar IMEPg }\end{array}$ \\
\hline Diesel Injection Timing [CAD bTDC] & {$[$ from 15 to 50] } & {$[$ from 29 to 43] } \\
Diesel Injection Pressure [bar] & {$[1300,1700,2100]$} & {$[1700,2100]$} \\
Diesel Fuel Mass $[\mathrm{mg} / \mathrm{c}]$ & 50 & 45 \\
Intake Temperature $\left[{ }^{\circ} \mathrm{C}\right]$ & 47 & {$[43,53]$} \\
Intake Pressure $[$ bar-abs] & 1.85 & 3.75 \\
Exhaust Backpressure $[$ bar-abs] & 2.00 & 2.85 \\
IVC [CAD bBDC] & 35 & 57 \\
GF [\%] & 88 & 95 \\
\hline
\end{tabular}

Table 7: Boundaries and Limitations for engine operation

\begin{tabular}{ll}
\hline Boundaries & \\
$\mathrm{NO}_{x}\left[\mathrm{mg} / \mathrm{Nm}^{3} @ 5 \% \mathrm{O}_{2}\right]$ & 500 \\
$\mathrm{IMPG}[\mathrm{bar}]$ & 50 \\
\hline Limitations & \\
Cylinder Pressure [bar] & 200 \\
COV [\%] & 5 \\
\hline
\end{tabular}


excessively early pilot injection timing. Boundaries were related to maximum pressure oscillations in the combustion chamber and maximum $\mathrm{NO}_{x}$ emission level according to TA Luft emission legislation, which was presented in the introduction section.

Engine testing was complemented with simulations of HRF equivalence ratio and spatial distributions in the combustion chamber at experimental SoC. Experimental data from representative operating points was used as input to the 1-D model, as described in previous sections.

\section{Combustion Development Results}

\subsection{Effects of Diesel Injection Pattern}

In this section, the effects of pilot injection timing and pilot injection pressure on combustion development at medium and high load are presented. All tests were carried out at fixed engine speed 1000rpm $(50 \mathrm{~Hz}$ power generation applications). Specific engine settings for the different engine loads are included in Table 6 .

\subsubsection{Medium Load Conditions}

Traditionally, combustion phasing in pilot ignited natural gas engines is controlled via diesel injection timing. However, this behaviour is not consistent throughout the entire operating range. As shown in Figure 5, when diesel injection timing is advanced, the combustion process is started earlier in the cycle. This behaviour is consistent until injection timings around 30CAD bTDC, when an important change of the combustion behaviour appears. From this point, advancing diesel timings results in later combustion phasing. Moreover, the effect of injection pressure is reversed and substantially amplified. In the first stage, defined as late pilot injection cases, an increment in injection pressure at constant injection timing causes earlier combustion phasing, while on the other hand, for early pilot injection cases, combustion phasing is retarded when injection pressure is increased. 


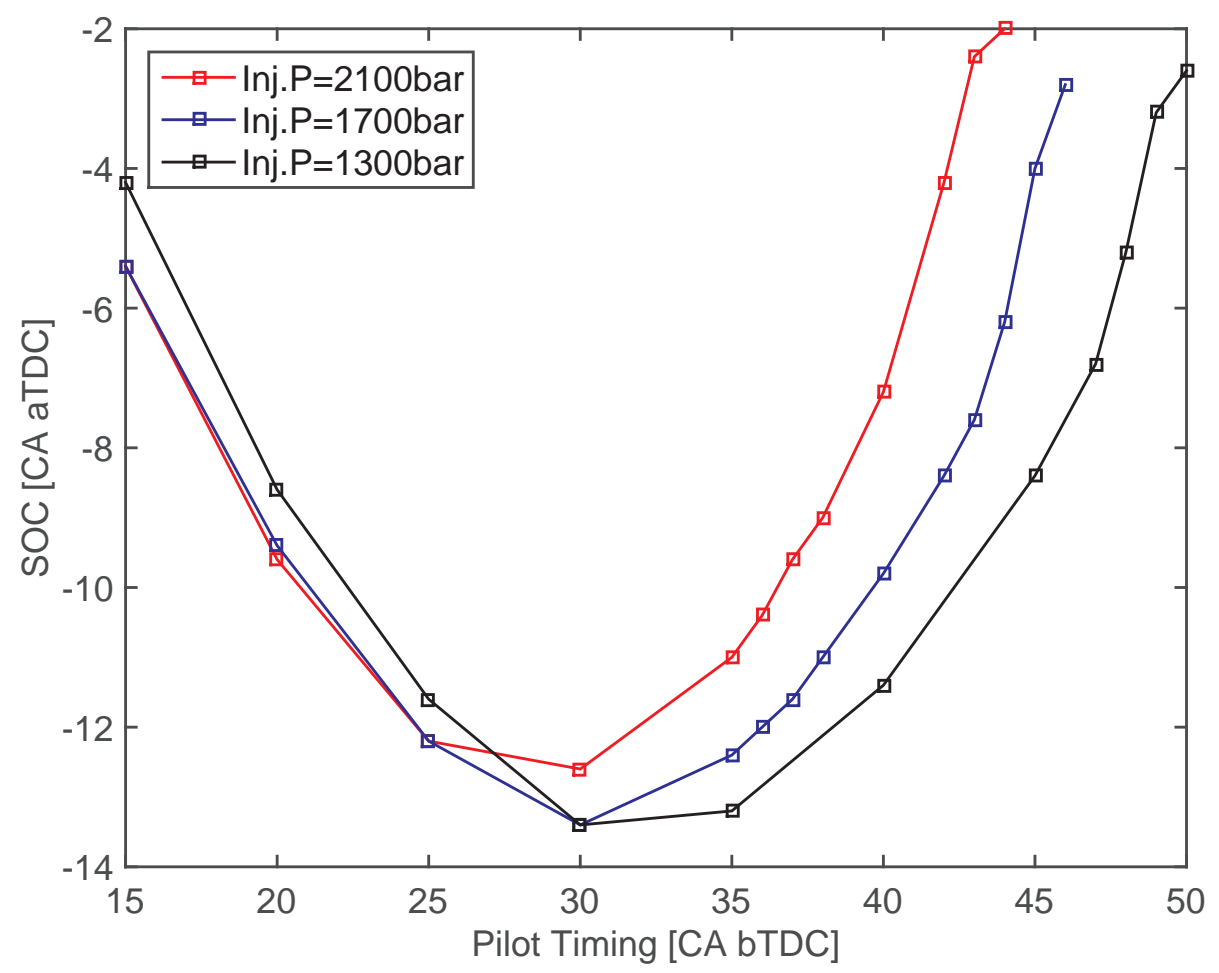

Figure 5: SoC versus pilot injection timing for different pilot injection pressures. Medium load conditions 

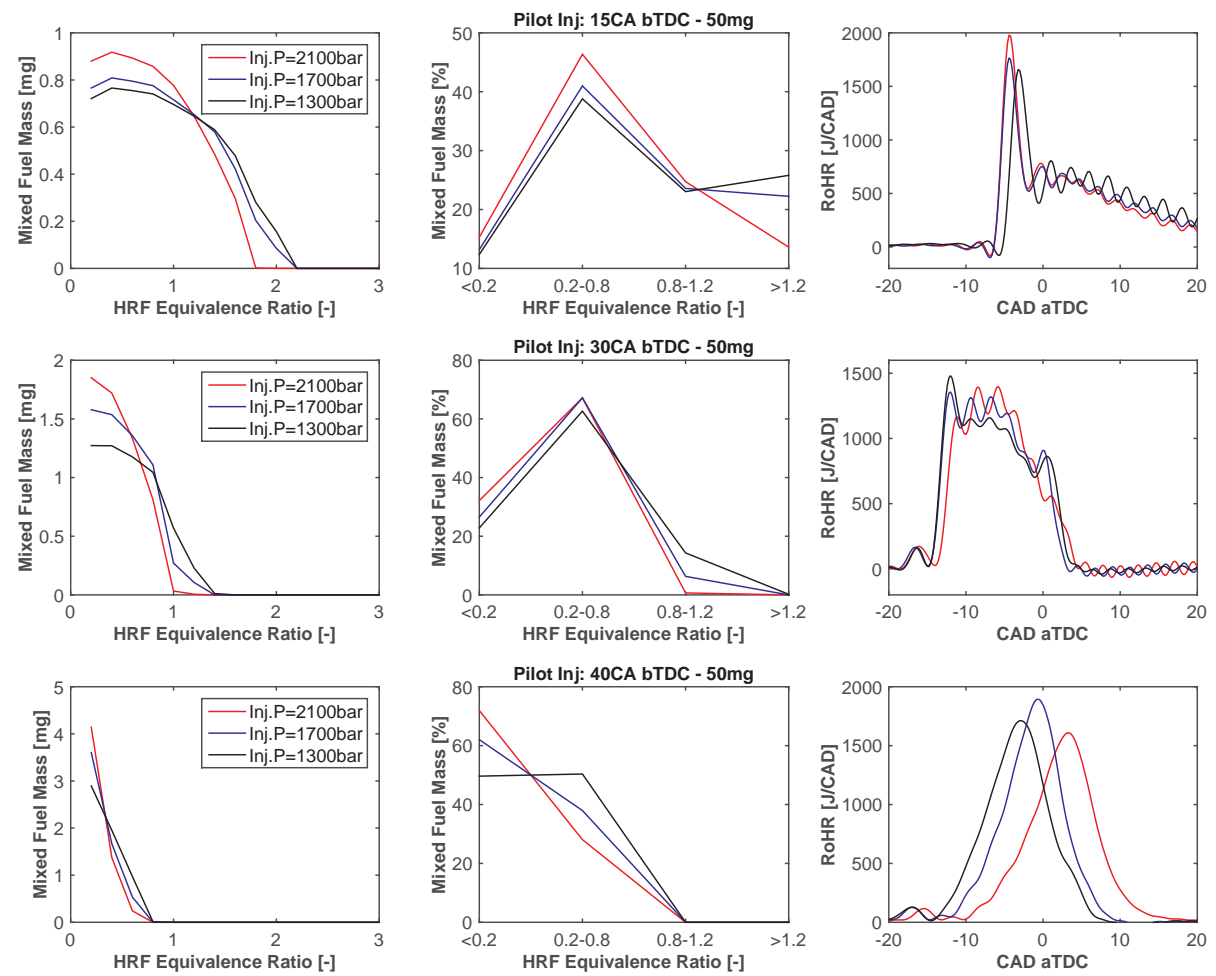

Figure 6: RoHR and HRF equivalence ratio distribution at SoC comparison between late and early pilot injection timings. Medium load conditions 
These two trends are represented in Figure 6, where RoHR coupled with results from pilot injection simulations are presented for two representative conditions (15 and 40 CAD bTDC pilot injection timings). As explained in the model description, the results represent an estimation of HRF equivalence ratio distribution at the experimental SoC. In the case of 15 CAD bTDC pilot injection, the mixing process occurs later in the compression stroke and consequently, higher pressure and temperature are present in the combustion chamber at SoI. For this reason, ignition delay is shorter compared to early injection timings and there is a significant amount of $\mathrm{HRF}$ at reactive equivalence ratio $\left(0.8<\phi_{H R F}<1.2\right)$ at SoC. This means that there is a large degree of HRF stratification in the combustion chamber. Reducing injection pressure causes a decrease of the mixing rate and consequently less mass of HRF under reactive equivalence ratios is present in the mixture. For this reason, SoC is delayed compared to scenarios with higher injection pressure. In all cases, this stratification causes a large RoHR premixed peak, followed by a slow flame propagation process due to lean LRF-air mixture conditions. Changes in injection pressure result in different SoC timings but combustion rates in both RoHR stages remained essentially unaltered. Thus, increments of pilot injection pressure at constant pilot injection timing under late pilot injection conditions cause a decrease of ignition delay but the same combustion characteristics prevail.

On the other hand, early pilot injection leads to the opposite trend. The longer ignition delay means that most HRF is under lean conditions and no HRF under stoichiometric conditions is present in the combustion chamber at SoC. The higher the injection pressure, the leaner the HRF distribution, resulting in longer ignition delay. While for 2100bar injection pressure, $70 \%$ of $\mathrm{HRF}$ is at equivalence ratios below 0.2 , in the case of 1300 bar injection pressure, the HRF mass at equivalence ratios below 0.2 is reduced to $50 \%$, and consequently more reactive conditions trigger start of combustion earlier in the cycle. However, changes in injection pressure also affect combustion rate, since a clear change ${ }_{30}$ in the RoHR initial slope is observed, which suggests that the combustion rate within the LRF-air mixture is affected by HRF distribution in the combustion 
chamber. In summary, increments of pilot injection pressure at constant pilot injection timing under early pilot injection conditions cause an increase of the ignition delay and both SoC and combustion rates are affected.

In Figure 5, the turning point of the three curves is located at $30 \mathrm{CAD}$ bTDC. Therefore, these conditions were also simulated and they are included in Figure6. It can be observed that combustion phasing starts to move towards TDC when there is no presence of HRF under stoichiometric ratio at SoC. From this point, acceptable combustion phasing is obtained by further advancing the pilot injection timing in order to create enough HRF mixing and dilution, which in combination with thermodynamic conditions, triggers ignition of HRF and translates into sustained LRF combustion. The reduced stratification of HRF makes the mixture more sensitive to thermodynamic conditions since well-mixed mixture and long ignition delay under early pilot injection conditions result in Gaussian-shaped heat release and consequently an HCCI-like combustion event. This explains the different magnitude of injection pressure effects on SoC between late and early pilot injection timings observed in Figure 5 .

Figure 7 shows that effects of increasing pilot injection pressure on SoC are more significant for long ignition delay conditions. Short ignition delay conditions imply that a decrease in pilot injection pressure causes delayed $\mathrm{SoC}$ while for long ignition delay conditions, SoC is advanced with lower pilot injection pressures. Moreover, changes in ignition delay when pilot injection timing is closer to TDC severely affect SoC, while SoC is less sensitive to ignition delay for early pilot injection conditions. This behaviour has been explained by the HRF equivalence ratio distribution in the combustion chamber. Early injection timing results in a well-mixed mixture of HRF, LRF and air, which autoignites when thermodynamic conditions trigger HRF auto-ignition and results in a Gaussian-shaped heat release process, similar to HCCI or RCCI conditions (single or dual fuel conditions).

According to Figure 5, the same combustion phasing can be obtained with two different HRF distributions in the combustion chamber. These two HRF distribution are depicted in Figure 8 (15 CAD bTDC) and Figure 9 (40 CAD 


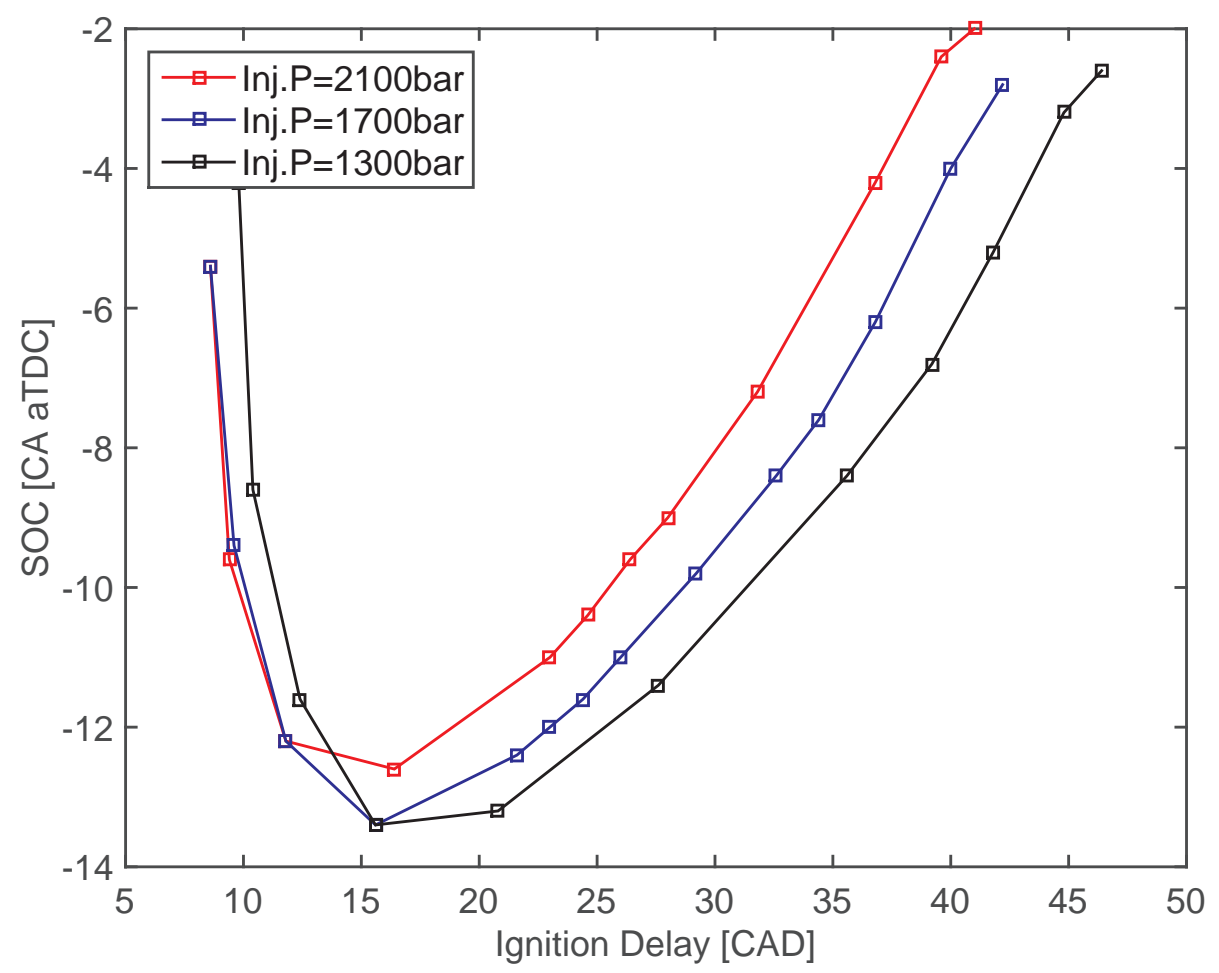

Figure 7: SoC versus ignition delay for different pilot injection pressures. Medium load conditions 


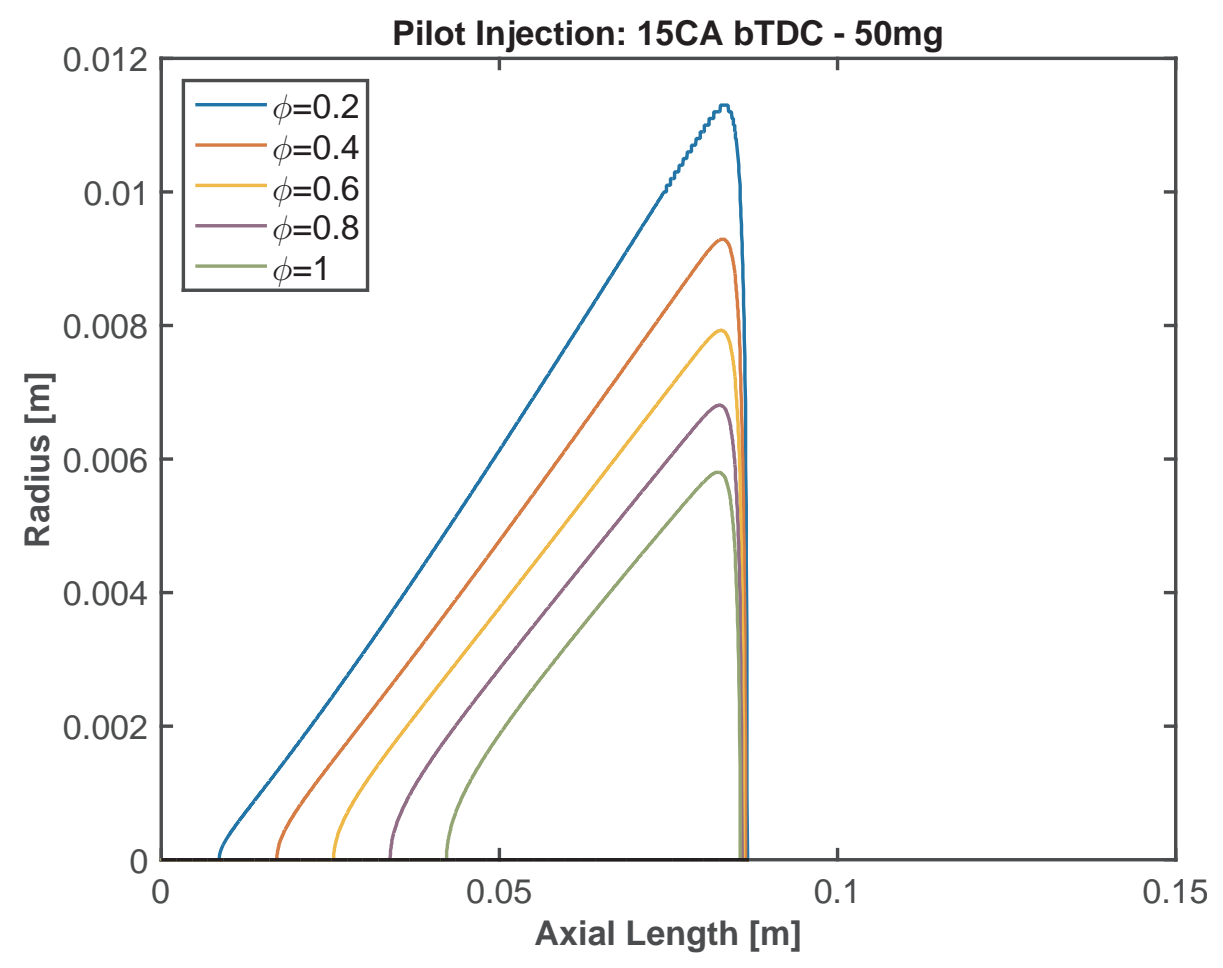

Figure 8: HRF equivalence ratio spatial distribution for 15 CAD bTDC pilot injection timing at SoC. Medium load conditions. 1700 bar injection pressure

bTDC), where the simulated radius and axial length of the HRF spray for two different pilot injection timings are analysed. For late injection timing, the $\mathrm{HRF}$ is located closer to the injector nozzle. This suggests that ignition is also located closer to the nozzle and consequently only LRF is present outside the HRF spray area. Consequently, a slow flame propagation process is established from the HRF to the LRF area, as can be observed in the RoHR in Figure 6. On the other hand, early pilot timing results in HRF well mixed with LRF and air further away from injector nozzle. Consequently, the reactivity of the gas mixture is improved which results in a more volumetric combustion event, as described previously.

These two different scenarios result in different combustion durations. While under late injection conditions LRF combustion is excessively slow, earlier pilot 


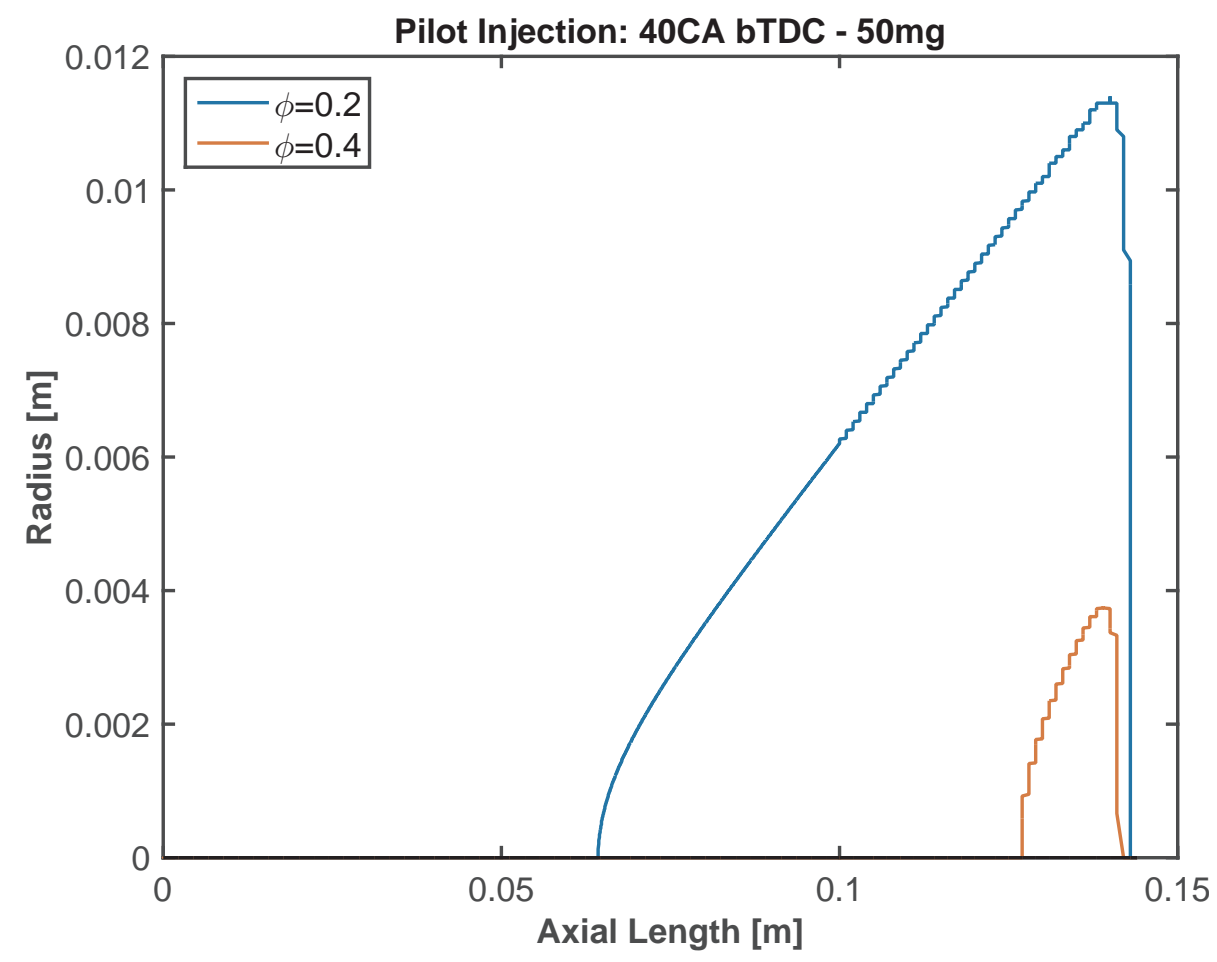

Figure 9: HRF equivalence ratio spatial distribution for $40 \mathrm{CAD}$ bTDC pilot injection timing at SoC. Medium load conditions. 1700 bar injection pressure 


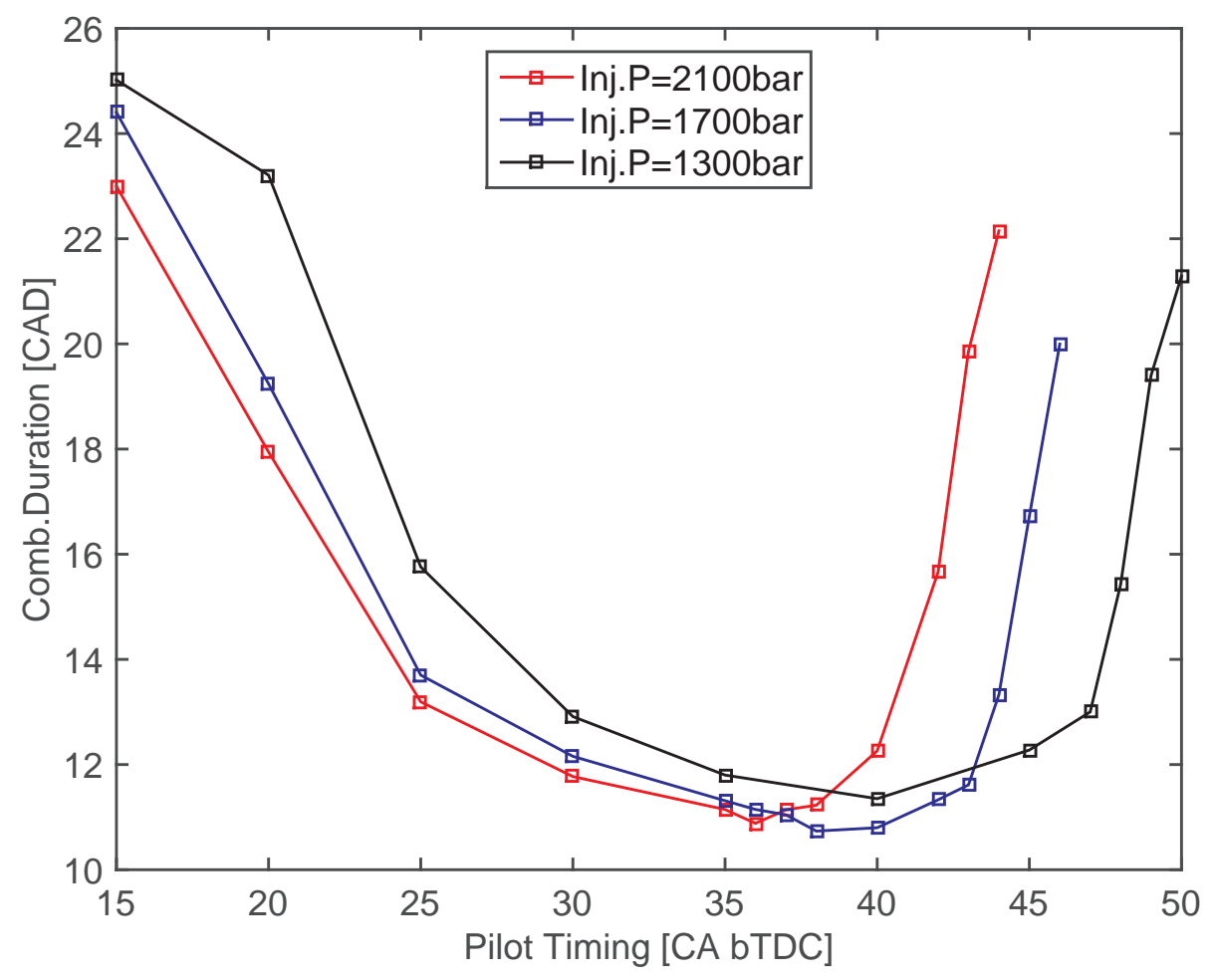

Figure 10: Combustion duration versus pilot injection timing for different pilot injection pressures. Medium load conditions

injection allows a faster LRF combustion rate due to increased mixture reactivity. This behaviour is consistent until pilot injection timings around 35-40 CAD bTDC when RoHR takes place during the expansion stroke and combustion duration increases again. This trend is presented in Figure 10

\subsubsection{High Load Conditions}

Engine load was increased via higher boosting level and higher LRF flow rate, maintaining a value of 0.5 global equivalence ratio. This strategy implied that HRF was significantly diluted compared to medium load conditions. As explained in the previous section, thermodynamic conditions are expected to have a significantly higher impact on combustion characteristics at diluted conditions. For this reason, two different intake temperature conditions were 


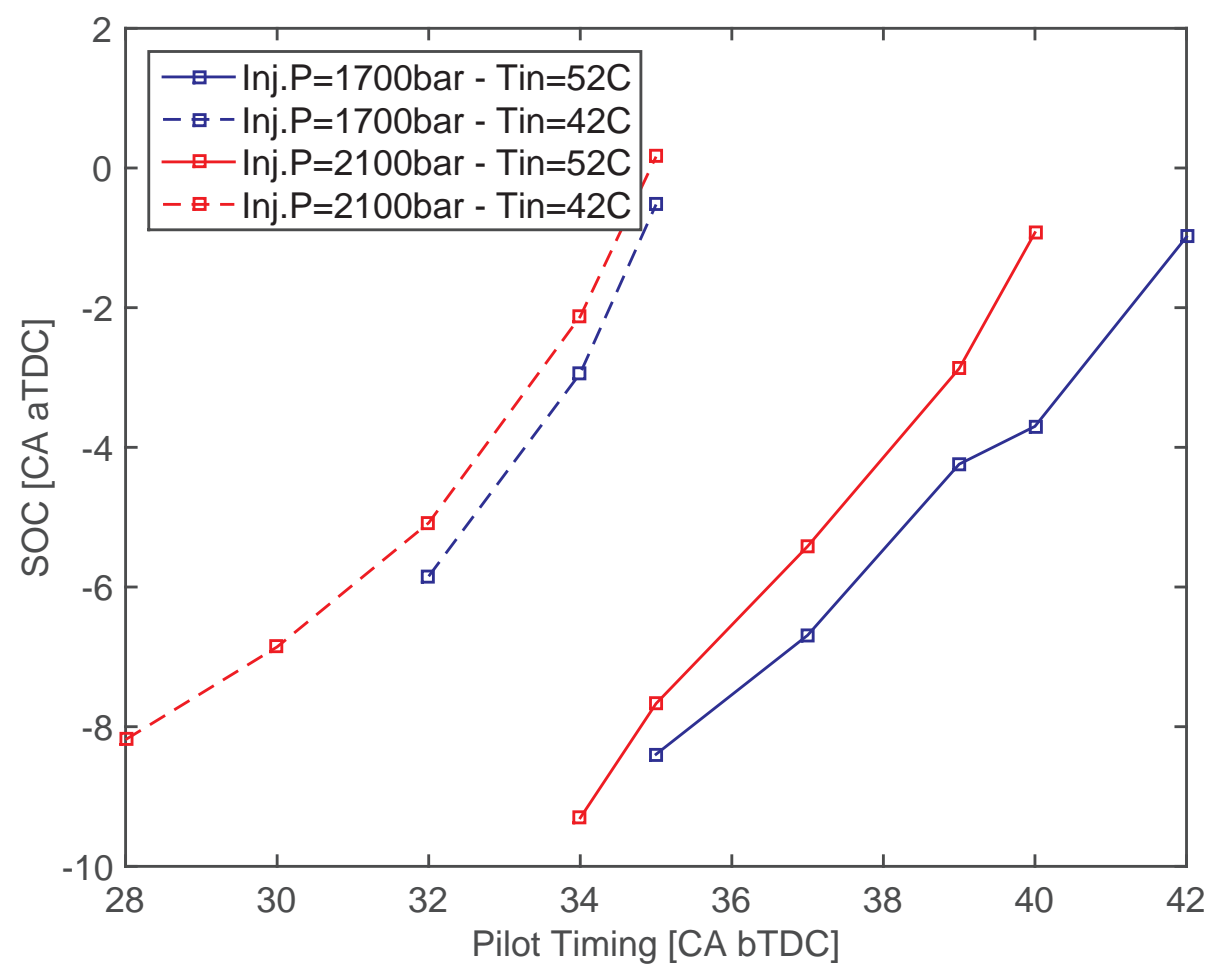

Figure 11: SoC versus pilot injection timing for different pilot injection pressures. High load conditions. Dashed lines $=$ low intake temperature level $/$ Solid lines $=$ high intake temperature level

tested at high load operation, in order to evaluate its impact on the combustion process.

As described in the methodology section, high load operation was limited by maximum peak cylinder pressure with retarded injection timing, while stability became a limiting factor for excessively early pilot injection timing. This translates into a narrower pilot injection timing window compared to medium load operation, as observed in Figure 11.

The effects of pilot injection pressure on SoC at high load operation follow similar trends as for medium load conditions. As in medium load conditions, simulations of HRF equivalence ratio distribution are presented in Figure 12 for two different pilot injection timings and intake temperatures at different pilot 

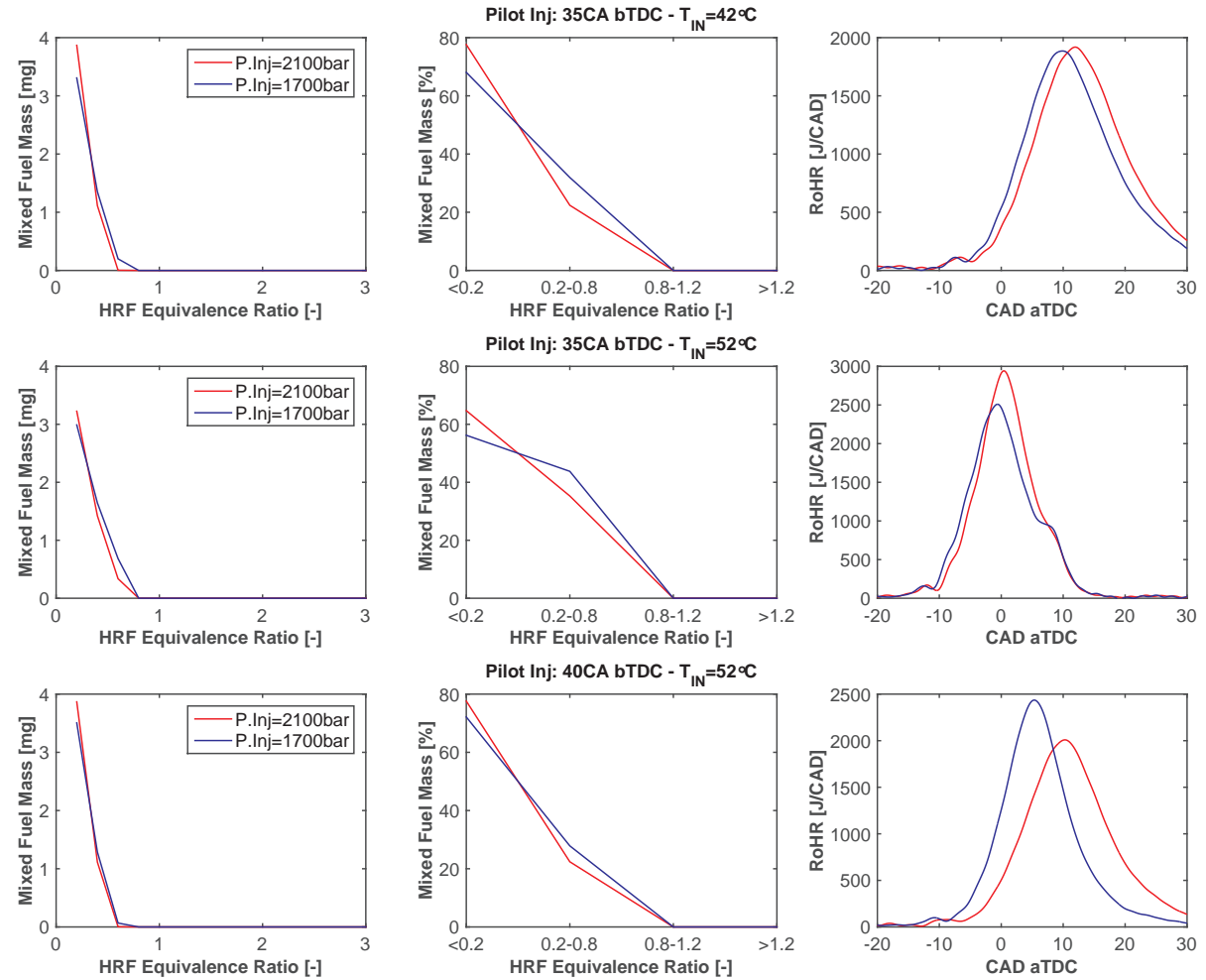

Figure 12: RoHR and HRF equivalence ratio distribution at $\mathrm{SoC}$ for 2 different pilot injection timings and intake temperatures. High load conditions 
injection pressures. In this figure, rows 1 and 2 relate to temperature effects while pilot injection timings are evaluated in rows 2 and 3.

Increased mixture temperature decreases mixture density. This reduces mix-

pilot ignition combustion. The results show that stratification plays a dominant role on combustion characteristics and, simultaneously, accurate control of com- 

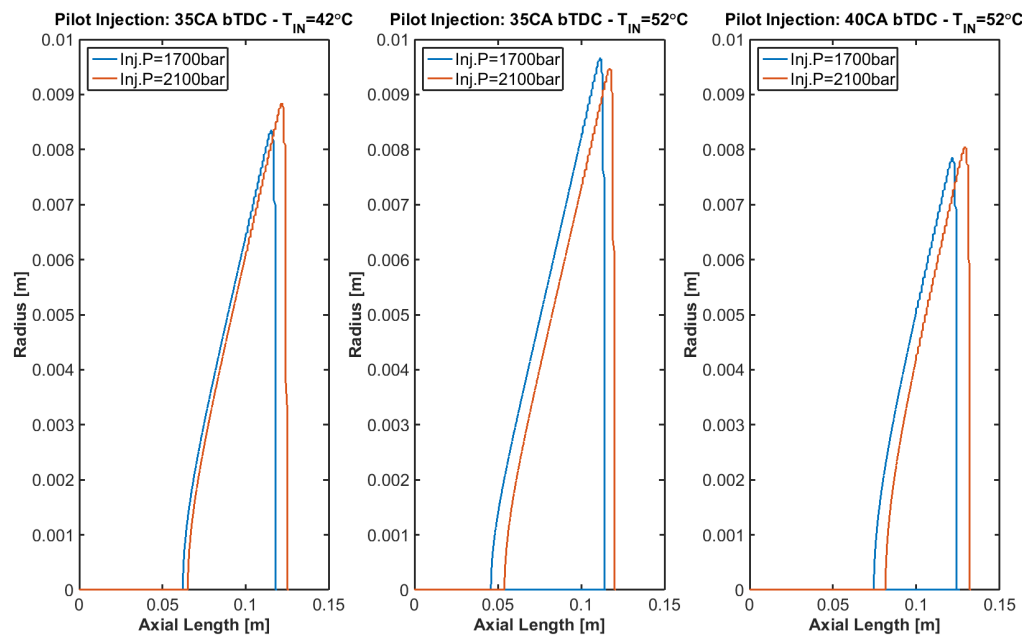

Figure 13: RoHR and HRF equivalence ratio distribution at SoC for 2 different pilot injection timings and intake temperatures. High load conditions

bustion temperature is required at high GF conditions. This control could be achieved in different ways, and one of the most effective methods to reduce combustion temperatures is reduced compression ratio via variable valve timings, which is presented in the following section.

\subsection{Effects of Effective Compression Ratio}

Autoignition of diesel fuel is governed by fuel distribution and thermodynamic conditions, since there is little induced turbulence in the combustion chamber. Therefore, an investigation about the effects of different thermodynamic properties of the mixture was performed in order to complement the studies on diesel fuel distribution. This included changes in intake valve closing timing, which resulted in different effective compression ratios. Effective compression ratio varied from 11.8 to 9.9 when IVC was changed from 35 to 57 CAD bBDC.

As expected, lower compression ratio results in delayed combustion due to an increase of HRF ignition delay, caused by the lower compression temperature. Figure 14 shows how the operating range is limited when compression 


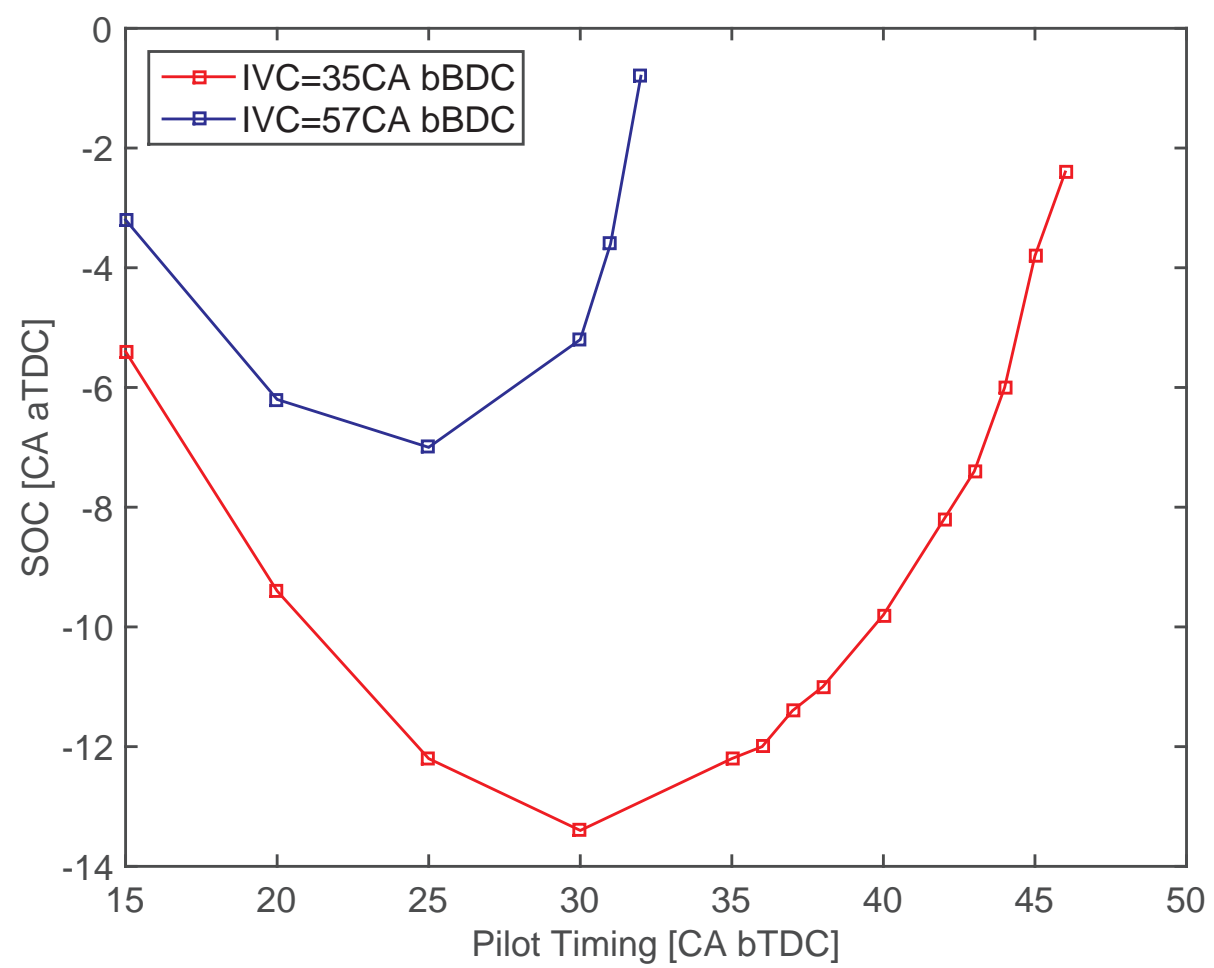

Figure 14: Pilot timing versus SoC for different IVC timings. Medium load conditions

ratio is reduced. Instabilities prevent operation beyond $30 \mathrm{CAD}$ bTDC, while higher compression ratio guaranteed stable combustion down to $45 \mathrm{CAD}$ bTDC pilot injection timing. Early IVC reduces bulk temperature so the effect of diesel stratification in the combustion chamber is compensated and therefore admissible (after TDC) combustion phasing is obtained.

As seen in Figure 15, there are no significant differences in HRF distribution which could explain such a drastic change in RoHR. Consequently, the changes in the combustion process must be linked to the thermodynamic change in the combustion chamber. Both temperature at $\mathrm{SoC}$ and maximum average combustion temperature are presented in Figure 16. As expected, earlier IVC results in lower combustion temperatures. This combined with unaltered HRF distribution at $\mathrm{SoC}$ results in poor HRF ignitability and poor ignition process for pilot injection timings beyond $30 \mathrm{CAD}$ bTDC, and consequently the operating 

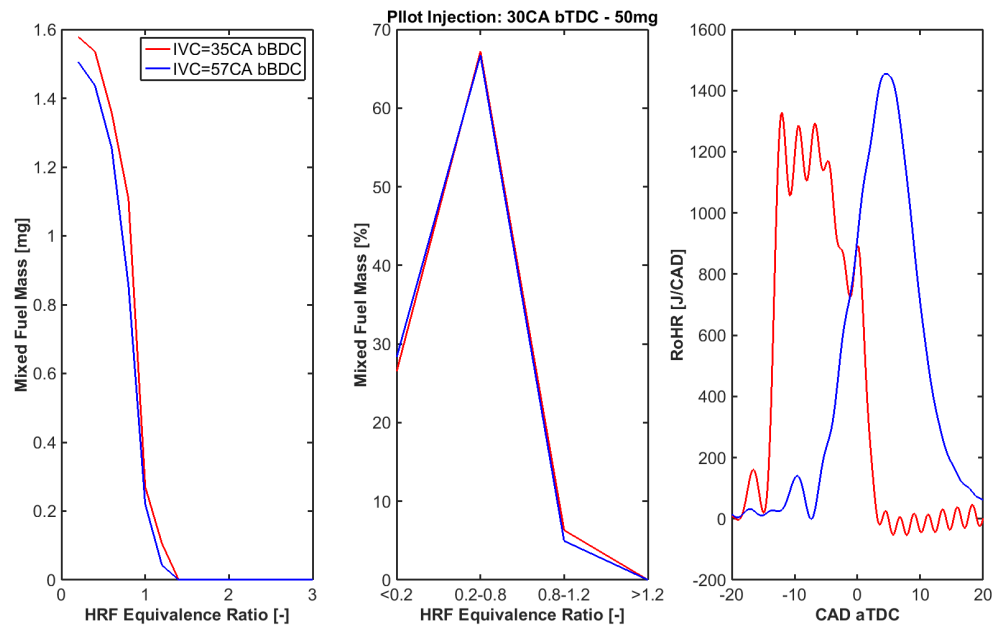

Figure 15: RoHR and diesel equivalence ratio at SoC comparison between 35 and 57CA bBDC IVC. Medium load conditions. 1700bar pilot injection pressure

range is narrower than for IVC $35 \mathrm{CAD}$ bBDC.

As explained in the previous sections, the presence of stoichiometric HRF areas in the combustion chamber are likely to promote early combustion phasing. However, these results show that stratification of diesel fuel combined with reduced pressure and temperature can be used to control the combustion phasing, which has a direct effect on efficiency, stability and engine-out emissions. This hypothesis results in a trade-off between combustion temperatures and stratification which must be assessed depending on engine constraints. This discussion is introduced in the next sections.

\section{Performance and $\mathrm{NO}_{x}$ Emissions}

\subsection{Combustion Stability}

This analysis is mainly based on medium load conditions, since high load operation was limited by peak cylinder pressure. As observed in Figure 17 combustion stability deteriorates at two different operating areas. The first area of instabilities occurs under late pilot injection conditions, while the second 

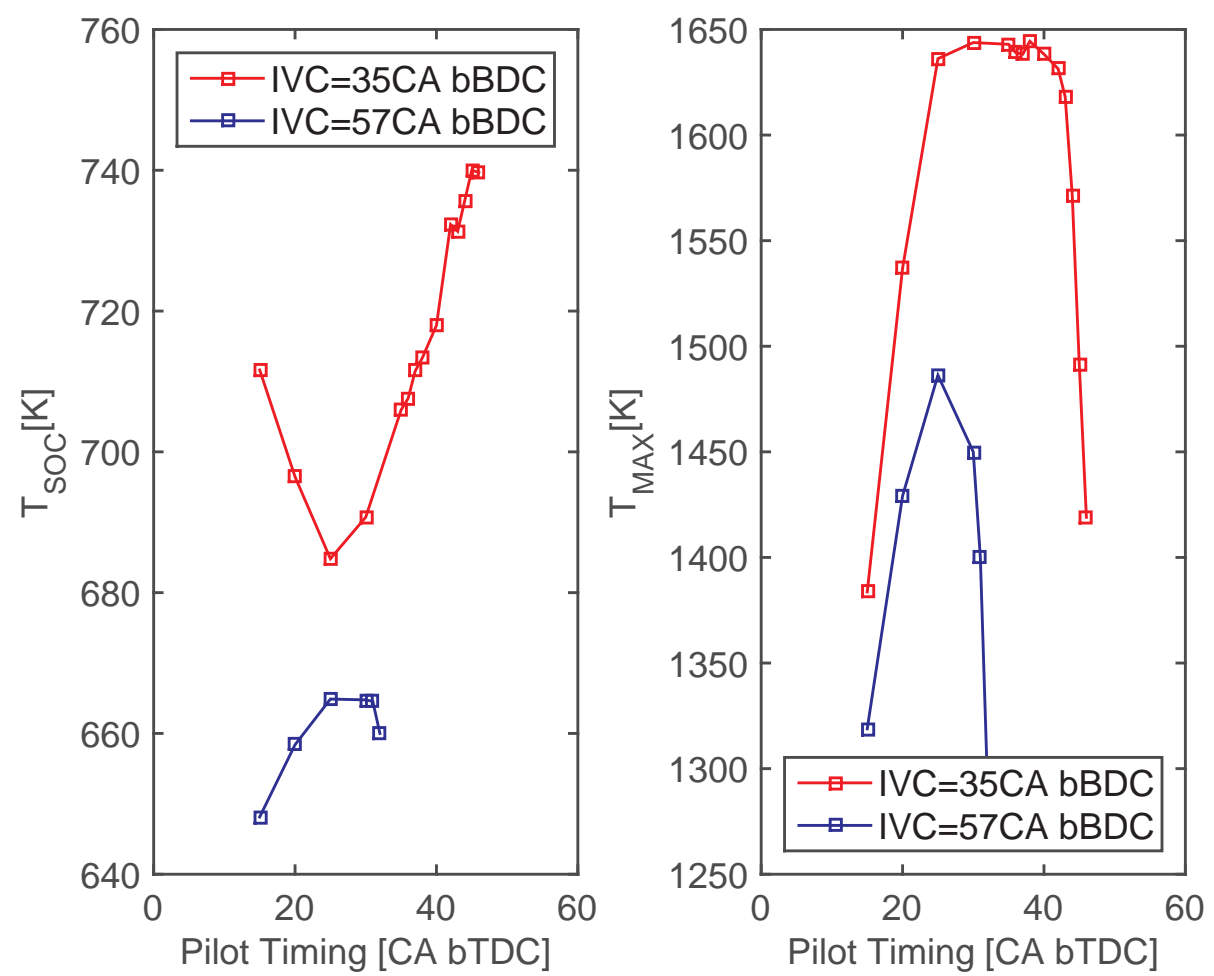

Figure 16: Pilot timing versus temperature at SoC and maximum combustion temperature (ideal gas, single-zone model) for different IVC timings. Medium load conditions. 1700bar pilot injection pressure 


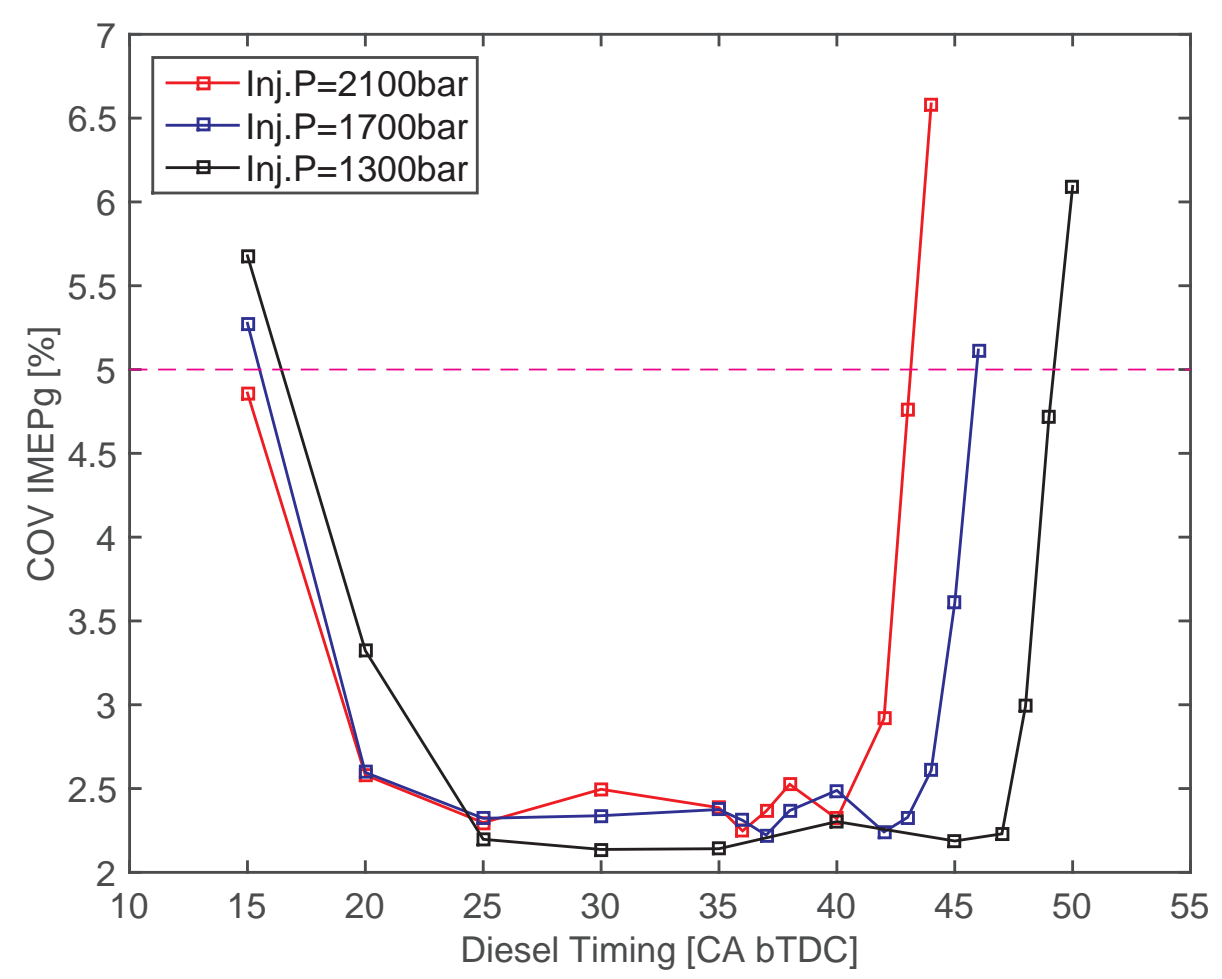

Figure 17: COV versus pilot injection timing for different pilot injection pressures. Medium load conditions

one is associated with the earliest pilot injection timings. Consequently, the mechanisms differ between the two different scenarios.

In the first case, high degree of HRF stratification is present in the combustion chamber, and as explained in previous sections, this results in a robust ignition of the HRF. At the same time, ignition delay is short enough to prevent the HRF from a high degree of mixing with the LRF and air in the surroundings. Consequently, the mixture around the HRF zone is basically LRF and air and, after the premixed heat release, a long and slow combustion is established. This fact, combined with lower cylinder pressure and temperature during the expansion stroke, reduces combustion stability. By contrast, early pilot injection conditions also show instabilities. Under these conditions, long ignition delay allows a high degree of mixing of HRF and consequently more HRF at 


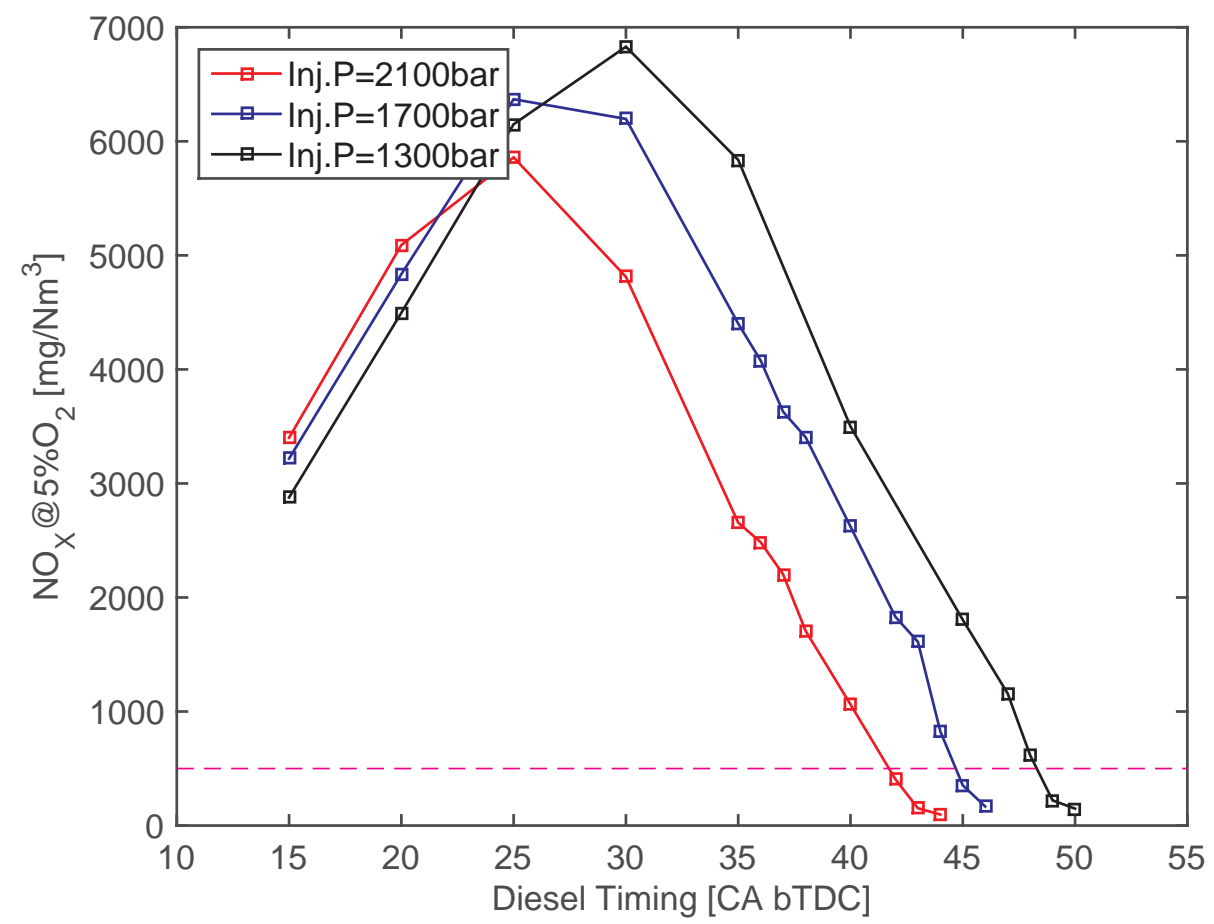

Figure 18: $\mathrm{NO}_{x}$ versus pilot injection timing for different pilot injection pressures. Medium load conditions

low equivalence ratios. This enhanced mixing results in a more reactive mixture of HRF, LRF and fuel. However, if the ignition delay is excessively long, the HRF is so diluted that no sustained combustion can be obtained. This change is sharper than for late pilot injection conditions, where the transition is smoother. These hypotheses are supported by Figure 8 and Figure 9 , where simulation results for $\mathrm{HRF}$ spatial and equivalence ratio distributions at $\mathrm{SoC}$ for two different pilot injection timings were presented.

\section{2. $N O_{x}$ Emissions}

Figure 18 represents $\mathrm{NO}_{x}$ emissions for the different pilot injection timings evaluated at different pilot injection pressures at medium load conditions. The dashed line indicates the TA Luft $\mathrm{NO}_{x}$ emission limit for compression ignition dual fuel engines running on gas $\left(500 \mathrm{mg} / \mathrm{Nm}^{3}\right.$ at $\left.5 \% \mathrm{O}_{2}\right)$. For late pilot condi- 
tions, advancing $\mathrm{HRF}$ injection timing results in an increase of $\mathrm{NO}_{x}$ emissions. This is connected to the explanation presented in Figure 6. Improved mixing leads to a larger HRF mass at reactive equivalence ratios, which triggers the combustion process earlier in the cycle and results in higher heat release peak. This effect also translates into CA50 timing occurring earlier in the cycle, and $\mathrm{NO}_{x}$ emissions increase due to higher combustion temperatures. However, when HRF mixing time is increased and SoC begins to shift towards TDC, $\mathrm{NO}_{x}$ emissions are reduced. This trend is maintained until combustion stability decreases due to poor HRF ignitability. As depicted in Figure 19, HRF injection pressure does not have a clear effect on $\mathrm{NO}_{x}$ emission at constant SoC or CA50 for the earliest pilot timings, while dispersion increases for late pilot conditions. This suggests that $\mathrm{NO}_{x}$ emissions are mainly controlled by HRF combustion for pilot timings close to TDC, while combustion phasing determined by mixture reactivity becomes the dominant factor for early pilot conditions.

Regarding effective compression ratio effects, the reduced combustion temperatures linked with earlier IVC have a direct impact on $\mathrm{NO}_{x}$ emissions. Up to $80 \%$ reduction of $\mathrm{NO}_{x}$ levels with earlier IVC suggests that variable valve timing is an effective way of reducing combustion temperatures for knock-free high load operation.

\subsection{Performance Summary}

In this section the fulfilment of the different constraints and limitations is discussed. As observed in Figure 21, late pilot conditions turn out in excessively high $\mathrm{NO}_{x}$ emissions in all cases. On the other hand, early pilot conditions allow an injection window of $8 \mathrm{CAD}$ (from 42 to $50 \mathrm{CAD}$ bTDC) where engineout $\mathrm{NO}_{x}$ levels are under legislation without the need of an after-treatment system and no HRF ringing or end gas autoignition is detected. However, the combustion stability window is slightly narrower than $\mathrm{NO}_{x}$ window. In this case, the stability limit is located at 49 CAD bTDC. Consequently, stable engine operation at medium load with engine-out $\mathrm{NO}_{x}$ emissions below TA-Luft limits is possible via adjustments of HRF pilot injection pressure and timing in a 7 

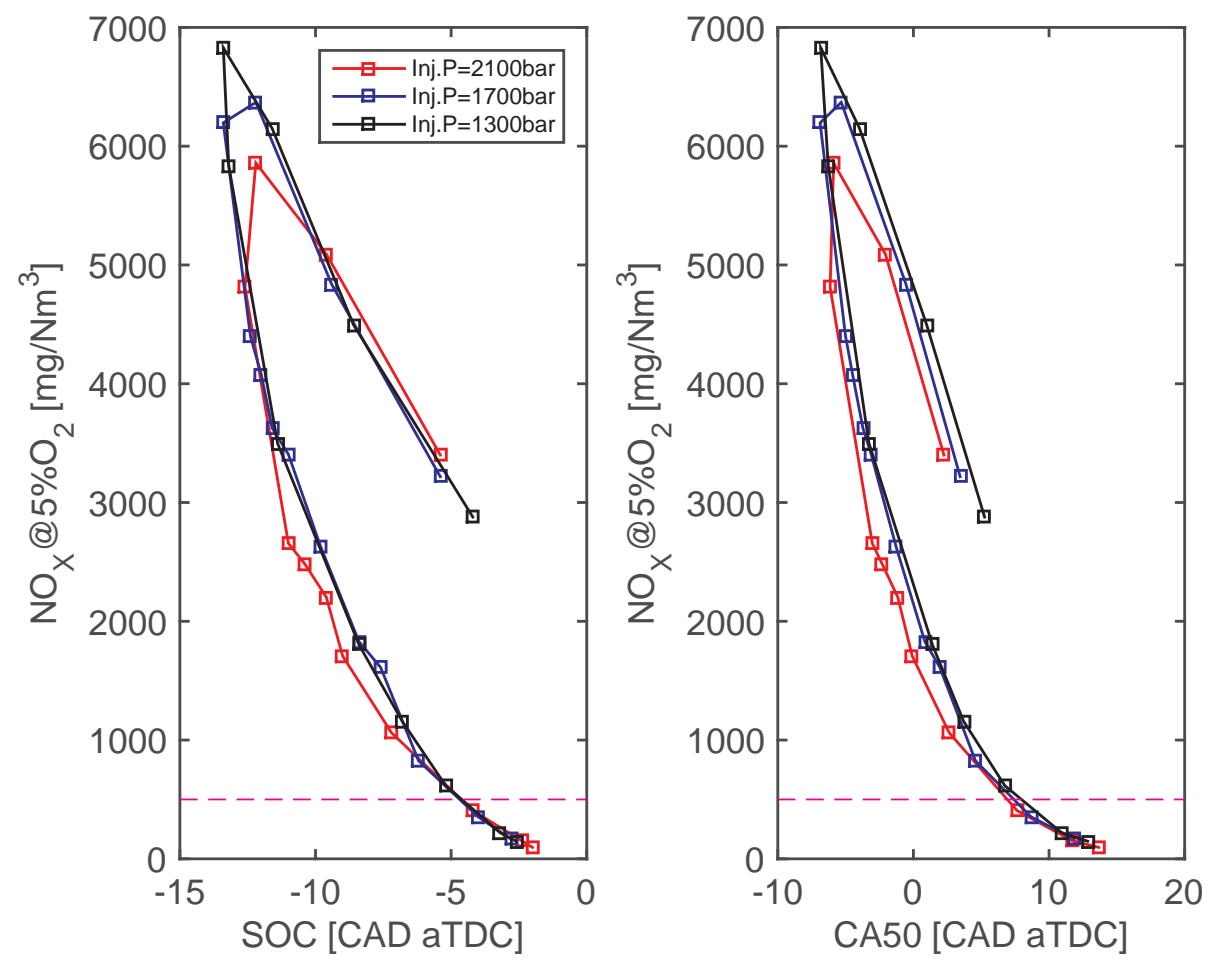

Figure 19: $\mathrm{NO}_{x}$ versus SoC and CaA50 for different pilot injection pressures. Medium load conditions 


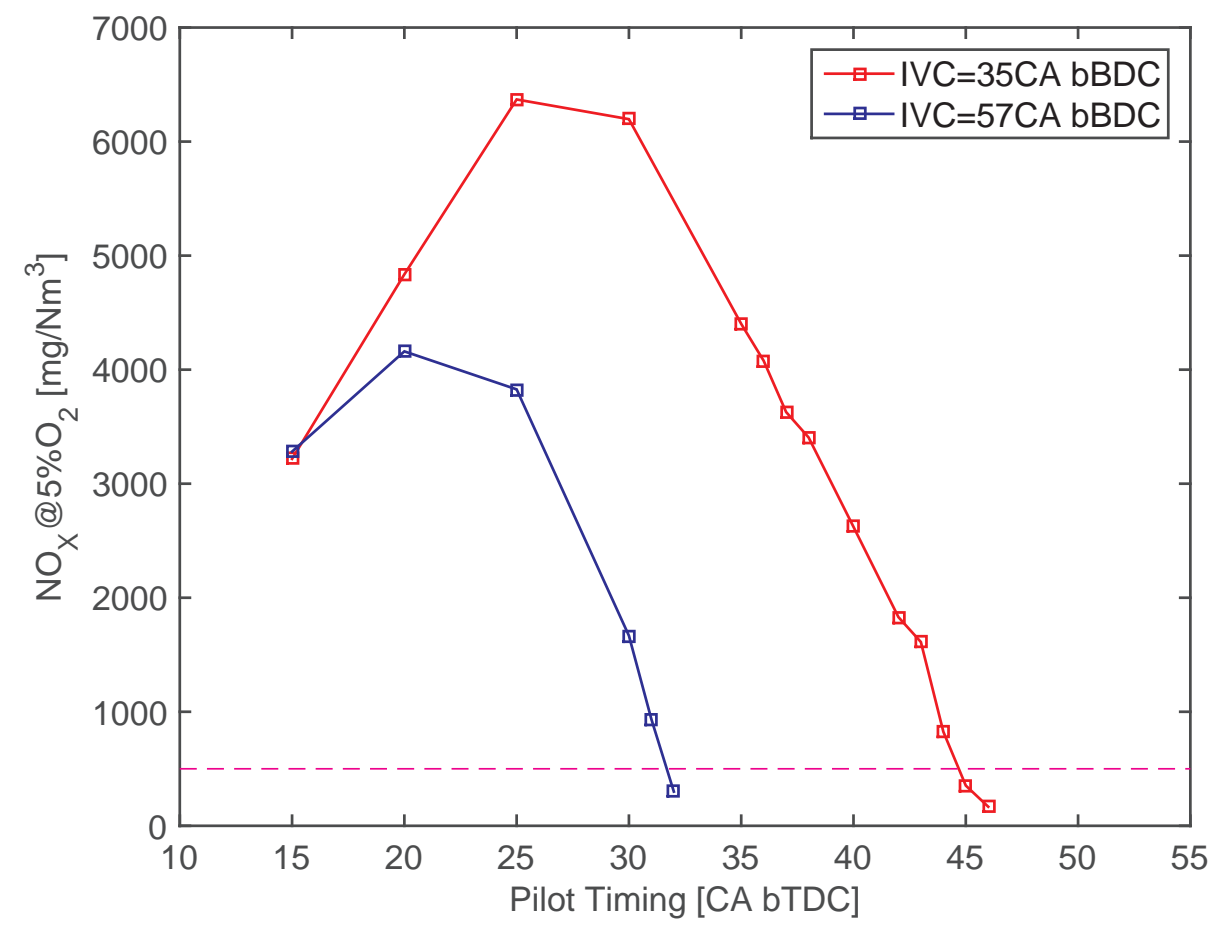

Figure 20: $\mathrm{NO}_{x}$ versus pilot injection timing for different IVC timings. Medium load conditions. 1700bar pilot injection pressure 

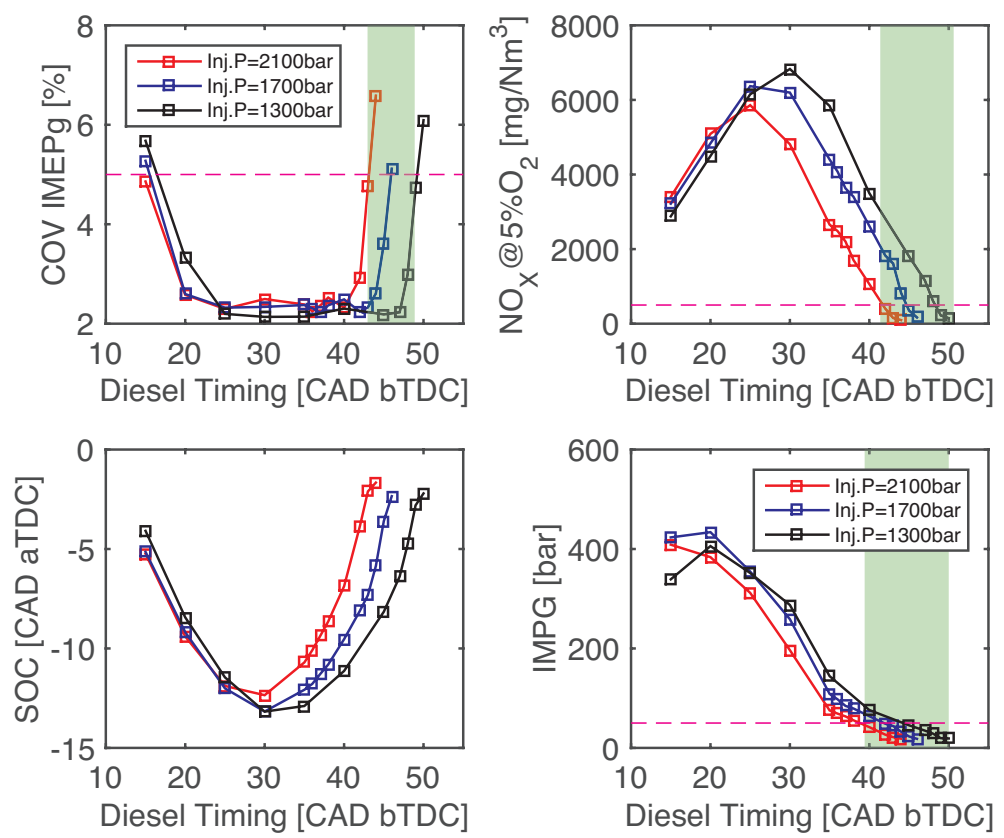

Figure 21: $\mathrm{NO}_{x}, \mathrm{COV}, \mathrm{SoC}$ and IMPG versus pilot injection timing for different pilot injection pressures. Medium load conditions 
CAD pilot injection window located between 42 and 49 CAD bTDC. A similar trend is observed at high load operation, although suitable injection window is even narrower (3 CAD).

The location of this window and its range obviously depends on operating conditions such as HRF mass, engine load, effective compression ratio, etc. so results should be interpreted qualitatively. However, these results demonstrate how appropriate HRF stratification control can lead to stable combustion fulfilling emission legislation without the need of an after-treatment system in marine and stationary applications.

\section{Conclusions}

In this paper, an investigation about the effects of HRF fuel autoignition characteristics on pilot ignited lean LRF combustion has been presented. Diesel and compressed natural gas were selected as HRF and LRF respectively. HRF fuel autoignition is governed by fuel distribution and thermodynamic conditions in the combustion chamber. Consequently, different scenarios where these conditions were varied have been presented and explained. Simulations of 1dimensional HRF spray pattern behaviour support the experimental data to explain trends observed in the experimental phase. The main conclusions from this study are:

- HRF fuel distribution in the combustion chamber highly affects not only start of combustion but also mixture reactivity and consequently, LRF combustion characteristics.

- $\mathrm{HRF}$ injection pressure has a larger impact on $\mathrm{NO}_{x}$ for early injection timings than for late injection timings. This is due to the effects of HRF distribution on start of combustion timing. For late injection timings, these effects have a lower weight on the start of combustion timing, since thermodynamic conditions result in short ignition delays. However, injection timings outside the ignitability region for the HRF cause an increase of the ignition delay which enhances the HRF mixing process and 
a well-mixed mixture is present in the combustion chamber at SoC, which translates into Gaussian-shaped HCCI-like heat release.

- Simulations confirmed the hypothesis that large HRF proportion around stoichiometric condition leads to high premixed heat release peak. This causes a peak in $\mathrm{NO}_{x}$ emissions and an increased risk for abnormal combustion events. However, combustion stability is not guaranteed since lean LRF conditions dominate in most of the combustion chamber.

- Consequently, to reduce nitrogen oxides without significantly compromising combustion efficiency, it is crucial to control HRF spatial distribution. Excessively lean conditions will lead to poor ignition characteristics, which combined with lean LRF conditions, will deteriorate combustion stability. On the other hand, excessively rich areas will contribute significantly to $\mathrm{NO}_{x}$ emissions and, despite of sustained ignition, flame propagation throughout the LRF mixture will be poor, since the absence of HRF will reduce mixture reactivity.

- These results prove the importance of combustion phasing control on pilot ignited lean natural gas combustion under strict $\mathrm{NO}_{x}$ emissions targets. The operating window where all constraints are respected (stability, abnormal combustion, and emissions) is very narrow (in the range of a few CA degrees) and requires cycle-to-cycle control strategies to be implemented for increased robustness.

\section{Acknowledgements}

Special thanks to all technicians of the Division of Combustion Engines at Lund University involved in the project. Financial support from The KCFP Engine Research Center is graciously acknowledged by the authors. The authors acknowledge Wärtsilä Corporation for supporting this research and providing the test engine. The author J. Monsalve-Serrano acknowledges the financial support from the Universitat Politècnica de València under the grant Ayudas 
Para la Contratación de Doctores para el Acceso al Sistema Español de Ciencia, Tecnología e Innovación

\section{References}

[1] Study of emission control and energy efficiency measures for ships in the port area, Tech. rep., International Maritime Organization (2015).

[2] Studies on the feasibility and use of LNG as a fuel for shipping, Tech. rep., International Maritime Organization (2016).

[3] F. Adamchak, A. Adede, LNG as marine fuel, in: 17th International Conference and Exhibition on Liquified Natural Gas, Poten and Partners, 2013.

[4] G. McTaggart-Cowan, K. Mann, N. Wu, S. Munshi, An efficient directinjection of natural gas engine for heavy duty vehicles, in: SAE Technical Paper, SAE International, 2014. doi:10.4271/2014-01-1332.

[5] G. McTaggart-Cowan, K. Mann, J. Huang, A. Singh, B. Patychuk, Z. X. Zheng, S. Munshi, Direct injection of natural gas at up to 600 bar in a pilot-ignited heavy-duty engine, SAE Int. J. Engines 8 (2015) 981-996. doi:10.4271/2015-01-0865.

[6] J. Hiltner, A. Loetz, S. Fiveland, Unburned hydrocarbon emissions from lean burn natural gas engines - sources and solutions, in: 28th CIMAC World Congress on Combustion Engine, no. 32, CIMAC, 2016.

[7] E. Faghani, P. Kheirkhah, C. W. Mabson, G. McTaggart-Cowan, P. Kirchen, S. Rogak, Effect of injection strategies on emissions from a pilot-ignited direct-injection natural-gas engine- part II: Slightly premixed combustion, in: SAE Technical Paper, SAE International, 2017. doi:10.4271/2017-01-0763.

[8] B. Wang, T. Li, L. Ge, H. Ogawa, Optimization of combustion chamber geometry for natural gas engines with diesel micro-pilot-induced ignition, 
Energy Conversion and Management 122 (2016) 552 - 563. doi:10.1016/ j.enconman.2016.06.027.

[9] H. Korpi, G. Hellén, L. O. Liavåg, A. D. Miceli, Development of exhaust gas aftertreatment systems applied to modern high efficiency four-stroke medium-speed engines, in: 28th CIMAC World Congress on Combustion Engine, no. 97, CIMAC, 2016.

[10] R. Papagiannakis, C. Rakopoulos, D. Hountalas, D. Rakopoulos, Emission characteristics of high speed, dual fuel, compression ignition engine operating in a wide range of natural gas/diesel fuel proportions, Fuel 89 (7) (2010) 1397 - 1406, 17th International Symposium on Alcohol Fuels. doi:10.1016/j.fuel.2009.11.001.

[11] S. Taniguchi, M. Masubuchi, K. Kitano, K. Mogi, Feasibility study of exhaust emissions in a natural gas diesel dual fuel (DDF) engine, in: SAE Technical Paper, SAE International, 2012. doi:10.4271/2012-01-1649.

[12] N. N. Mustafi, R. R. Raine, S. Verhelst, Combustion and emissions characteristics of a dual fuel engine operated on alternative gaseous fuels, Fuel 109 (2013) 669 - 678. doi:10.1016/j.fuel.2013.03.007.

[13] G. A. Karim, Dual-Fuel Diesel Engines, CRC Press, 2015, doi:10.1201/b18163.

[14] A. P. Carlucci, D. Laforgia, R. Saracino, G. Toto, Combustion and emissions control in dieselmethane dual fuel engines: The effects of methane supply method combined with variable in-cylinder charge bulk motion, Energy Conversion and Management 52 (89) (2011) 3004-3017. doi:https: //doi.org/10.1016/j.enconman.2011.04.012.

[15] D. Lata, A. Misra, Analysis of ignition delay period of a dual fuel diesel engine with hydrogen and LPG as secondary fuels, International Journal of 635 Hydrogen Energy 36 (5) (2011) 3746 - 3756. doi:https://doi.org/10. 1016/j.ijhydene.2010.12.075. 
[16] E. Salaun, J. Apeloig, F. Grisch, C.-E. Yvonnet, B. Nicolas, F. Dionnet, Optical investigation of ignition timing and equivalence ratio in dual-fuel cng/diesel combustion, in: SAE Technical Paper, SAE International, 2016. doi: 10.4271/2016-01-0772

[17] O. Badr, G. Karim, B. Liu, An examination of the flame spread limits in a dual fuel engine, Applied Thermal Engineering 19 (10) (1999) 1071 - 1080. doi:https://doi.org/10.1016/S1359-4311(98)00108-2

[18] J. Benajes, A. Garca, J. M. Pastor, J. Monsalve-Serrano, Effects of piston bowl geometry on reactivity controlled compression ignition heat transfer and combustion losses at different engine loads, Energy 98 (2016) $64-77$. doi:https://doi.org/10.1016/j.energy.2016.01.014

[19] J. Benajes, A. Garca, J. Monsalve-Serrano, I. Balloul, G. Pradel, An assessment of the dual-mode reactivity controlled compression ignition/conventional diesel combustion capabilities in a EURO VI mediumduty diesel engine fueled with an intermediate ethanol-gasoline blend and biodiesel, Energy Conversion and Management 123 (2016) 381 - 391. doi:https://doi.org/10.1016/j.enconman.2016.06.059.

[20] J. Benajes, A. Garca, J. Monsalve-Serrano, V. Boronat, Achieving clean and efficient engine operation up to full load by combining optimized RCCI and dual-fuel diesel-gasoline combustion strategies, Energy Conversion and Management 136 (2017) 142 - 151. doi:https://doi.org/10.1016/j. enconman.2017.01.010.

[21] N. Dronniou, J. Kashdan, B. Lecointe, K. Sauve, D. Soleri, Optical investigation of dual-fuel cng/diesel combustion strategies to reduce co2 emissions, SAE Int. J. Engines 7 (2014) 873-887. doi:10.4271/2014-01-1313.

[22] M. Herranen, K. Huhtala, M. Vilenius, G. Liljenfeldt, The electro-hydraulic valve actuation EHVA for medium speed diesel engines - development steps with simulations and measurements, in: SAE Technical Paper, SAE International, 2007. doi:10.4271/2007-01-1289. 
[23] C.S.Draper, Pressure waves accompanying detonation in the internal combustion engine, Journal of the Aeronautical Sciences 5 (6) (1938) 219-226. doi:10.2514/8.590

[24] J. Benajes, S. Molina, A. García, J. Monsalve-Serrano, R. Durrett, Performance and engine-out emissions evaluation of the double injection strategy applied to the gasoline partially premixed compression ignition spark assisted combustion concept, Applied Energy 134 (2014) 90 - 101. doi:10.1016/j.apenergy.2014.08.008.

[25] G. Brecq, O. L. Corre, Modeling of in-cylinder pressure oscillations under knocking conditions: Introduction to pressure envelope curve, in: SAE Technical Paper, SAE International, 2005. doi:10.4271/2005-01-1126.

[26] J. A. Eng, Characterization of pressure waves in HCCI combustion, in: SAE Technical Paper, SAE International, 2002. doi:10.4271/2002-01-2859.

[27] B. Johansson, O. Andersson, P. Tunestal, M. Tuner, Combustion engines. Vol. 1, Department of Energy Sciences, Lund University, Lund, 2014.

[28] J. V. Pastor, J. J. López, J. M. García, J. M. Pastor, A 1D model for the description of mixing-controlled inert diesel sprays, Fuel 87 (1314) (2008) 2871 - 2885. doi:10.1016/j.fuel.2008.04.017.

[29] J. Desantes, J. Pastor, J. García-Oliver, J. Pastor, A 1D model for the description of mixing-controlled reacting diesel sprays, Combustion and

口 Flame 156 (1) (2009) 234 - 249. doi:10.1016/j.combustflame.2008.10. 008.

[30] J. V. Pastor, J. M. García-Oliver, J. M. Pastor, W. Vera-Tudela, Onedimensional diesel spray modeling of multicomponent fuels, Atomization and Sprays 25 (6) (2015) $485-517$.

[31] A. García, J. Monsalve-Serrano, B. Heuser, M. Jakob, F. Kremer, S. Pischinger, Influence of fuel properties on fundamental spray characteristics and soot emissions using different tailor-made fuels from biomass, 
Energy Conversion and Management 108 (2016) 243 - 254. doi:10.1016/ j.enconman.2015.11.010.

[32] J. Benajes, S. Molina, A. García, J. Monsalve-Serrano, Effects of direct injection timing and blending ratio on RCCI combustion with different low reactivity fuels, Energy Conversion and Management 99 (2015) 193 - 209. doi:10.1016/j.enconman.2015.04.046. 